\title{
MAP1B Light Chain Modulates Synaptic Transmission via AMPA Receptor Intracellular Trapping
}

\author{
Rocío Palenzuela, ${ }^{1,2}$ Yolanda Gutiérrez, ${ }^{1}$ Jonathan E. Draffin, ${ }^{1}$ Argentina Lario, ${ }^{1}$ Marion Benoist, ${ }^{1}$ \\ and $\oplus^{\top}$ José A. Esteban ${ }^{1}$ \\ ${ }^{1}$ Department of Neurobiology, Centro de Biología Molecular Severo Ochoa (Consejo Superior de Investigaciones Científicas-Universidad Autónoma de \\ Madrid), Madrid 28049, Spain, and 2School of Experimental Sciences, Universidad Francisco de Vitoria, Pozuelo de Alarcón, Madrid 28223, Spain
}

The regulated transport of AMPA-type glutamate receptors (AMPARs) to the synaptic membrane is a key mechanism to determine the strength of excitatory synaptic transmission in the brain. In this work, we uncovered a new role for the microtubule-associated protein MAP1B in modulating access of AMPARs to the postsynaptic membrane. Using mice and rats of either sex, we show that MAP1B light chain (LC) accumulates in the somatodendritic compartment of hippocampal neurons, where it forms immobile complexes on microtubules that limit vesicular transport. These complexes restrict AMPAR dendritic mobility, leading to the intracellular trapping of receptors and impairing their access to the dendritic surface and spines. Accordingly, increasing MAP1B-LC expression depresses AMPAR-mediated synaptic transmission. This effect is specific for the GluA2 subunit of the AMPAR and requires glutamate receptor interacting protein 1 (GRIP1) interaction with MAP1B-LC. Therefore, MAP1B-LC represents an alternative link between GRIP1-AMPARs and microtubules that does not result in productive transport, but rather limits AMPAR availability for synaptic insertion, with a direct impact on synaptic transmission.

Key words: cytoskeleton; GluA1; GluA2; GRIP1; hippocampus; spine

Significance Statement

The ability of neurons to modify their synaptic connections, known as synaptic plasticity, is accepted as the cellular basis for learning and memory. One mechanism for synaptic plasticity is the regulated addition and removal of AMPA-type glutamate receptors (AMPARs) at excitatory synapses. In this study, we found that a microtubule-associated protein, MAP1B light chain (MAP1B-LC), participates in this process. MAP1B-LC forms immobile complexes along dendrites. These complexes limit intracellular vesicular trafficking and trap AMPARs inside the dendritic shaft. In this manner, MAP1B restricts the access of AMPARs to dendritic spines and the postsynaptic membrane, contributing to downregulating synaptic transmission.

\section{Introduction}

Postsynaptic AMPA-type glutamate receptors (AMPARs) mediate most excitatory synaptic transmission in the mammalian CNS

\footnotetext{
Received Feb. 22, 2017; revised Aug. 17, 2017; accepted Aug. 18, 2017.

Author contributions: R.P., M.B., and J.A.E. designed research;R.P., Y.G., J.E.D., and A.L. performed research; R.P., Y.G., J.E.D., A.L., M.B., and J.A.E. analyzed data; R.P., M.B., and J.A.E. wrote the paper.

This work was supported by the Spanish Ministry of Economy and Competitiveness (Grants SAF2014-57233-R and P(IN-2016-095). R.P. and M.B. were recipients of postdoctoral and predoctoral contracts, respectively, from the Instituto de Salud Carlos III. Y.G., J.E.D., and A.L. were recipients of predoctoral contracts from the Spanish Ministry of Economy and Competitiveness. M.B. was also the recipient of an award from the Fondation Bettencourt-Schuller (France). The monoclonal antibody against C-terminus GluA2 was developed by and obtained from the UC Davis/ National Institutes of Health (NIH) NeuroMab Facility, which is supported by NIH Grant U24NS050606 and maintained by the Department of Neurobiology, Physiology and Behavior, College of Biological Sciences, University of California, Davis. We thank María Muñoz for the preparation of specific DNA constructs for protein expression, Anna Chiarlone for related electrophysiological recordings that are not included in this manuscript, and the personnel at the fluorescence microscopy facility of the Centro de Biología Molecular Severo 0choa for expert technical assistance. The authors declare no competing financial interests.

A. Lario's present address: Department of Cellular and Molecular Pharmacology, University of California, San Francisco, CA.
}

(Hollmann and Heinemann, 1994; Traynelis et al., 2010). Considerable attention has been paid to the molecular machinery controlling the number and synaptic localization of AMPARs because these parameters are critical determinants for synaptic strength. Therefore, the trafficking of AMPARs in and out of the synaptic membrane is essential for synaptic plasticity events such as long-term potentiation (LTP) and long-term depression (LTD) (Derkach et al., 2007; Kessels and Malinow, 2009; Lüscher and Malenka, 2012; Herring and Nicoll, 2016), which are considered the cellular correlates for learning and memory (Bliss and Collingridge, 1993).

The sorting and targeting of AMPARs throughout intracellular membrane compartments is tightly regulated, from early bio-

Correspondence should be addressed to José A. Esteban, Centro de Biología Molecular Severo 0choa, Nicolas Cabrera 1, Madrid 28049, Spain. E-mail: jaesteban@cbm.csic.es.

DOI:10.1523/JNEUROSCI.0505-17.2017

Copyright $\odot 2017$ the authors $\quad 0270-6474 / 17 / 379945-19 \$ 15.00 / 0$ 
synthetic steps at the endoplasmic reticulum and Golgi complex to local endosomal trafficking in the vicinity of the synapse (Kennedy and Ehlers, 2006; Greger and Esteban, 2007; Shepherd and Huganir, 2007). A common theme in this regulation is the association of AMPARs with different multidomain scaffolding molecules that link AMPARs with key organizers of membrane trafficking and cytoskeletal dynamics (Elias and Nicoll, 2007). For example, glutamate receptor interacting protein 1 (GRIP1) couples AMPAR vesicles with motor protein transport (Setou et al., 2002; Shin et al., 2003; Hoogenraad et al., 2005; Heisler et al., 2014), whereas protein interacting with $\mathrm{C}$ kinase 1 (PICK1) associates AMPARs with regulators of the actin cytoskeleton (Rocca et al., 2008; Nakamura et al., 2011; Rocca et al., 2013).

In this context, an important mechanistic bridge may be provided by microtubule-associated proteins (MAPs). In addition to the role of microtubules in long-range AMPAR transport along dendrites (Setou et al., 2002; Heisler et al., 2014), there is also increasing evidence for local microtubule dynamics regulated by and affecting synaptic function (Hu et al., 2008; Jaworski et al., 2009; Hu et al., 2011; Merriam et al., 2011; Benoist et al., 2013). However, how the microtubule cytoskeleton is connected to AMPAR function at synapses is still far from clear.

In neurons, microtubules are decorated by MAPs, which interact with a variety of other proteins, including F-actin, small G-protein regulators, and scaffolding molecules (Halpain and Dehmelt, 2006). Among them, MAP1B is required for proper axon growth (Gonzalez-Billault et al., 2001; Gonzalez-Billault et al., 2002; Tymanskyj et al., 2012) and dendritic spine morphogenesis (Tortosa et al., 2011) in developing neurons. Nevertheless, MAP1B is expressed in the adult brain. It is present in the somatodendritic compartment (Tortosa et al., 2011), where it is needed to provide Racl activation during the regulated removal of AMPARs from synapses after LTD induction (Benoist et al., 2013). MAP1B is also expressed in presynaptic terminals, where it has been proposed to participate in synaptic vesicle fusion and presynaptic structure (Bodaleo et al., 2016). MAP1B is encoded as a polyprotein precursor that is subsequently cleaved into a heavy chain (MAP1B-HC) and a light chain (MAP1B-LC) (Hammarback et al., 1991). Both chains associate to form a 2:1 LC:HC multimeric protein complex on microtubules. Interestingly, it has been reported that MAP1B-LC exists well in excess over this stoichiometry, suggesting that it might have additional functions outside of the complex with the HC (Mei et al., 2000). In fact, MAP1B-LC binds and stabilizes microtubules independently from the HC (Noiges et al., 2002). MAP1B-LC also associates with AMPARs (Davidkova and Carroll, 2007) via its interaction with the AMPAR scaffolding molecule GRIP1 (Seog, 2004). Therefore, MAP1B-LC may provide a molecular link between AMPARs and stable microtubules that is separate from motor protein-dependent trafficking.

Here, we explored the potential role of microtubules as modulators of AMPAR synaptic function based on the bridging potential of MAPs. We have found that MAP1B-LC immobilizes AMPARs in intracellular compartments of the dendritic shaft, therefore preventing receptors from reaching dendritic spines and the synaptic membrane. In this manner, microtubule-dependent interactions act as decoys to limit the availability of circulating neurotransmitter receptors to support synaptic function.

\section{Materials and Methods}

DNA constructs, antibodies, and cell lines

The MAP1B-LC and MAP1B-HC recombinant proteins were made by in-frame ligation of the EGFP coding sequence with the LC sequence (aa 2100-2464) and the HC sequence (aa 1-2100) of MAP1B in
pMT22Tet and pMT17Tet plasmids (Tögel et al., 1998), respectively. Both plasmids were generously provided by Dr. Jesús Ávila (Centro de Biología Molecular Severo Ochoa, Madrid). The MAP1B-HC-GFP sequence was cloned into the FG12.CMV vector for biolistic transfection of hippocampal organotypic slices. The FG12.CMV vector (Verhaegen et al., 2006) was generously provided by Dr. María S. Soengas (Centro Nacional de Investigaciones Oncológicas, Madrid). MAP1B-LC tagged with EGFP, mCherry, or Dendra2 was cloned either in pSinRep5 for expression using Sindbis virus (Malinow et al., 2010) or in a vector bearing the CMV promoter for expression using the biolistic method (Lo et al., 1994; Wellmann et al., 1999; Gerges et al., 2005). The Dendra2tubulin construct (Jolly et al., 2010) was a kind gift from Vladimir I. Gelfand (Northwestern University Feinberg School of Medicine, Chicago). All GluA constructs were generously provided by Roberto Malinow (University of California, San Diego, California). To generate the deletion mutants of MAP1B-LC, the sequences corresponding to the GRIP1-binding domain of the wild-type protein (aa 2336-2459) or the microtubule-binding domain (aa 2210-2336) were removed by restriction digestion. The coding sequences of MAP1B-LC- $\Delta$ GBD-GFP and MAP1B-LC- $\triangle$ MBD-GFP were finally transferred into pSinRep5 vector. pBA-TfR-GFP and pJPA5-TfR-mCherry (Wang et al., 2008) were kindly provided by Dr Daniel Choquet (University of Bordeaux, Interdisciplinary Institute for Neuroscience, Bordeaux, France). The shRNA against MAP1B and the corresponding scrambled sequence (Benoist et al., 2013) were expressed using a lentiviral system.

Anti-MAP1B-LC and anti-MAP1B-HC antibodies were from Santa Cruz Biotechnology (sc-25729 and sc-8970, respectively, both used at 1/1000 dilution from the stock); anti-Tau1 antibody was from Millipore (clone PC1C6, used at $5 \mu \mathrm{g} / \mathrm{ml}$ ); anti-MAP2 antibody was from Covance (PCK-554P, used at 1/10000 dilution from the stock); anti-tyrosine tubulin and anti-acetylated tubulin were from Sigma-Aldrich (T9028 clone TUB-1A2 and T7451 clone 6-11B-1, respectively, used at 1/1000 dilution from the stock); and anti-detyrosinated tubulin was from Millipore (AB3201, used at 1/200 dilution from the stock). The antibodies against the N terminus of GluA1 and GluA2 were from Millipore (MAB2263 clone RH95 and MAB397 clone 6C4, respectively, used at 1/500 dilution from the stock), whereas the antibodies against the $\mathrm{C}$ terminus were from Abcam (AB31232, used at 1/1000 dilution from stock) and Neuromab (75-002, used at 1/1000 dilution from stock), respectively. The anti-GRIP1 antibody was from Millipore (ABN27, used at 1/500 dilution from stock). The BHK cell line for Sindbis virus infection and preparation of protein extracts was BHK21 (Hernandez and Brown, 2010).

\section{Recombinant protein expression and downregulation of} endogenous protein

Sindbis virus infection was used to overexpress GFP, MAP1B-LC, and MAP1B-LC mutants and Dendra2-tubulin (16-24h) in either hippocampal organotypic slices or primary cultures. MAP1B-HC was expressed (4-7 d) by biolistic transfection. Coexpression of either MAP1B-LC or MAP1B-LC mutants with recombinant GluA1 and GluA2 was also performed through biolistic transfection ( $48 \mathrm{~h}$ of expression). A lentiviral vector was used to transfect either CA1 neurons in hippocampal organotypic slices or primary hippocampal neurons with a construct encoding an shRNA against MAP1B or a scrambled version as a control (10-14 d of expression). Lipofectamine 2000 was used to transfect hippocampal primary neurons with transferrin receptor (TfR)-GFP and TfR-mCherry constructs.

\section{Electrophysiology}

Organotypic hippocampal slices were prepared from Wistar rat pups or CD1 mouse pups of either sex at postnatal days 5-7 and either infected with Sindbis virus for the expression of recombinant proteins or biolistically transfected or infected with lentivirus for shRNA expression. Voltage-clamp simultaneous whole-cell recordings were obtained from nearby pairs of infected (or transfected) and uninfected (or untransfected), control CA1 pyramidal neurons under visual guidance using fluorescence and transmitted light illumination. Recordings were performed at $29^{\circ} \mathrm{C}$ unless otherwise specified. The recording chamber was perfused with artificial cerebrospinal fluid (ACSF) saturated with $95 \%$ $\mathrm{O}_{2} / 5 \% \mathrm{CO}_{2}$ and containing the following (in $\mathrm{mm}$ ): $119 \mathrm{NaCl}, 2.5 \mathrm{KCl}, 1$ 
$\mathrm{NaH}_{2} \mathrm{PO}_{4}, 11$ D-glucose, $26 \mathrm{NaHCO}_{3}, 4 \mathrm{MgCl}_{2}, 4 \mathrm{CaCl}_{2}, 0.004$ 2-chloroadenosine, and 0.1 picrotoxin, $\mathrm{pH}$ 7.4. Patch recording pipettes ( 3 to 6 $\mathrm{M} \Omega$ ) were filled in with a solution containing the following (in $\mathrm{mM}$ ): 115 $\mathrm{CsMeSO}_{3}, 20 \mathrm{CsCl}, 10$ HEPES, $2.5 \mathrm{MgCl}_{2}, 4 \mathrm{Na}_{2}$-ATP, $0.4 \mathrm{Na}$-GTP, 10 Na-phosphocreatine, and 0.6 EGTA, pH 7.25. Synaptic responses were evoked with bipolar electrodes using single-voltage pulses (200 $\mu$ s, up to $25 \mathrm{~V})$. The stimulating electrodes were placed over Schaffer collateral fibers between 300 and $500 \mu \mathrm{m}$ from the recorded cells. Because only CA1 cells (and not CA3 cells) were infected or transfected, this configuration ensured that recombinant protein expression or endogenous protein knockdown is always performed exclusively in the postsynaptic cell. Synaptic AMPAR-mediated responses were measured at $-60 \mathrm{mV}$ and NMDAR-mediated responses at $+40 \mathrm{mV}$ at a latency when AMPARmediated responses had fully decayed $(100 \mathrm{~ms})$. In pep $2 \mathrm{~m}$ experiments, the peptide was included in the internal solution at $1 \mathrm{~mm}$ together with the protease inhibitors bestatin $(0.1 \mathrm{~mm})$ and leupeptin $(10 \mu \mathrm{M})$. NMDAR-dependent LTD was induced by pairing low-frequency presynaptic stimulation ( 300 pulses at $1 \mathrm{~Hz}$ ) with moderate postsynaptic depolarization $(-40 \mathrm{mV})$. mGluR-dependent LTD was induced by bath application of $50 \mu \mathrm{M}$ (RS)-3,5-dihydroxyphenylglycine (DHPG) for 5 min at $30^{\circ} \mathrm{C}$. Cells were held under current-clamp conditions without synaptic stimulation during DHPG application and $5 \mathrm{~min}$ afterward (Huber et al., 2001). These recordings were performed in the presence of $100 \mu \mathrm{M}(2 \mathrm{R})$-amino-5-phosphonovaleric acid (APV) to prevent any contribution to synaptic plasticity from NMDARs. LTP was induced with a pairing protocol by stimulating Schaffer collateral fibers (300 pulses at $3 \mathrm{~Hz}$ ) while depolarizing the postsynaptic cell at $0 \mathrm{mV}$. For rectification studies, AMPAR-mediated responses were recorded at $-60 \mathrm{mV}$ and +40 $\mathrm{mV}$ in the presence of $100 \mu \mathrm{m} \mathrm{APV}$ in the perfusion solution and $100 \mu \mathrm{M}$ spermine (a voltage-dependent channel blocker of GluA2-lacking AMPA receptors) in the internal solution. The rectification index was calculated as the ratio between the AMPAR synaptic responses at $-60 \mathrm{mV}$ and at $+40 \mathrm{mV}$. Electrophysiological recordings were performed with Multiclamp 700A/B amplifiers (Molecular Devices). Data acquisition and analysis were performed with pClamp software.

\section{Hippocampal primary cultures}

Hippocampi were dissected from embryonic day 19 (E19) Wistar rat embryos or E18 CD1 mouse embryos of either sex and cells were dissociated with trypsin. Neurons were plated onto poly-L-lysine-coated coverslips and cultured in Neurobasal medium supplemented with B27 and glutamine. Cells were maintained at $37^{\circ} \mathrm{C}$ and $5 \% \mathrm{CO}_{2}$ for either 1 week for distribution of endogenous MAP1B-HC and MAP1B-LC in axonal and somatodendritic compartments or 2-3 weeks for analysis of MAP1B-LC colocalization with posttranslationally modified tubulin, GluA2/GluA1 surface and total expression, and GRIP1 somatodendritic distribution.

\section{Pharmacological treatments}

Treatment with taxol $(10 \mathrm{nM})$ or vehicle $(0.01 \%$ DMSO) was performed by direct addition to the culture medium of the hippocampal slices. The incubation was maintained for $3 \mathrm{~h}$ and during the recordings in the circulating ACSF.

\section{Quantification of posttranslational tubulin modifications}

Total detyrosinated, acetylated, and tyrosinated tubulin levels were analyzed by SDS-PAGE and Western blot. Protein extracts were prepared from the CA1 subfield of organotypic hippocampal slices overexpressing either GFP or MAP1B-LC-GFP in a lysis buffer containing $20 \mathrm{~mm}$ HEPES, $100 \mathrm{~mm} \mathrm{NaCl}, 5 \mathrm{~mm}$ EDTA, and 1\% Triton X-100 in the presence of protease and phosphatase inhibitors from Roche (Complete Mini EDTA-free and phosSTOP). Protein amount was quantified by Bradford assay.

\section{Co-sedimentation assays}

Actin co-sedimentation. The actin co-sedimentation assay has been described previously (Pedrotti and Islam, 1995; Noiges et al., 2002). Briefly, purified actin from rabbit skeletal muscle (Cytoskeleton) was solubilized in $5 \mathrm{~mm}$ Tris, $\mathrm{pH} 8,0.2 \mathrm{~mm} \mathrm{CaCl}_{2}, 0.2 \mathrm{~mm} \mathrm{ATP}$, and $0.5 \mathrm{~mm}$ DTT and polymerized for $1 \mathrm{~h}$ at room temperature by the addition of $50 \mathrm{~mm} \mathrm{KCl}$,
$1 \mathrm{~mm}$ ATP, and $2 \mathrm{~mm} \mathrm{MgCl}_{2}$. Proteins of interest were expressed in $\mathrm{BHK}$ cells infected with Sindbis virus and extracted in $10 \mathrm{~mm}$ Tris- $\mathrm{HCl}, \mathrm{pH} 7.5$, and $1 \mathrm{~mm}$ DTT. Then, protein extracts and filamentous actin (mass ratio $1: 3$ ) were incubated for $1 \mathrm{~h}$ at room temperature and ultracentrifuged at $100,000 \times g$ for $20 \mathrm{~min}$ at $22^{\circ} \mathrm{C}$. Equal volumes of supernatants and pellets were analyzed by SDS-PAGE and Western blot.

Microtubule co-sedimentation. The microtubule co-sedimentation assay has been described previously (Campbell and Slep, 2011). Briefly, tubulin ( $>99 \%$ pure from bovine brain; Cytoskeleton) was incubated in 80 mм K-Pipes, 1 mм MgCl 2,1 mм EGTA, pH 6.8, supplemented with 1 $\mathrm{mm}$ GTP and $1 \mathrm{~mm} \mathrm{DTT} \mathrm{at} 4^{\circ} \mathrm{C}$ for $5 \mathrm{~min}$. The sample was then warmed at $37^{\circ} \mathrm{C}$ while adding $20 \mu \mathrm{M}$ taxol stepwise. Protein extracts were prepared as above. Taxol-stabilized microtubules protein extracts were mixed (mass ratio 3:1) and incubated at room temperature for $20 \mathrm{~min}$. Samples were then layered onto a glycerol cushion and centrifuged at $100,000 \times g$ for $30 \mathrm{~min}$ at $25^{\circ} \mathrm{C}$. To finish, supernatant and pellet fractions were collected, mixed with protein loading buffer, and analyzed by SDS-PAGE and Western blot.

\section{Biocytin filling}

CA1 neurons were filled with biocytin for 10-15 min after patching them in whole-cell configuration ( $0.5 \%$ biocytin in the internal solution). Slices were then fixed (4\% paraformaldehyde, $4 \%$ sucrose in PBS) overnight at $4^{\circ} \mathrm{C}$ and stained with streptavidin-Alexa Fluor 555 .

\section{Immunofluorescence}

Hippocampal organotypic slices were fixed overnight at $4^{\circ} \mathrm{C}$ in $4 \%$ paraformaldehyde with $4 \%$ sucrose in PBS. Blocking ( $1 \mathrm{~h}$ at room temperature) and incubation with primary antibodies (overnight at $4^{\circ} \mathrm{C}$ ) and secondary antibodies ( $1 \mathrm{~h}$ at room temperature) were done in a solution containing 3\% BSA, 2\% horse serum, and $0.3 \%$ Triton X-100 in PBS. Image acquisition was done with a confocal microscope (Zeiss, LSM 510) using a $63 \times$ oil-immersion objective. For primary neurons, two fixation methods were required. For MAP1B-HC/LC and GluA2/GluA1 immunostaing, fixation with $4 \%$ paraformaldehyde was performed for $20 \mathrm{~min}$ at room temperature. The blocking solution consisted of $0.22 \%$ fish gelatin in PBS without Triton X-100 (for surface staining) or supplemented with $0.1 \%$ Triton X-100 (for total staining). To analyze MAP1B-LC-GFP colocalization with posttranslationally modified tubulin and GRIP1 distribution, fixation was with methanol plus $1 \mathrm{~mm}$ EGTA for $20 \mathrm{~min}$ at $-20^{\circ} \mathrm{C}$ and blocking with $3 \%$ BSA, $0.1 \%$ Triton X-100, and $0.1 \%$ sodium azide in TBS. An inverted microscope (Axiovert 200; Zeiss) coupled to a CCD camera (Zeiss) was used for image acquisition $(63 \times$ oil immersion objective).

\section{Image analysis and quantification}

For quantification of MAP1B-LC colocalization with detyrosinated, acetylated, and tyrosinated tubulin, a line across one to two dendrites from each neuron was drawn. Using ImageJ, a profile of fluorescence intensities along each line was obtained for both channels. Distributions of normalized fluorescence intensity values in each channel were then averaged for all dendrites per condition.

For morphological analysis of dendritic spines, confocal images were acquired at a resolution of $1024 \times 1024$ pixels and a pinhole of $0.8 \mu \mathrm{m}$. $Z$-stacks were generated, each separated by $0.14 \mu \mathrm{m}$. Maximum intensity projections were used for quantification. Images were deconvoluted using Huygens software. Number, length, and head diameter of dendritic spines were quantified with NeuronStudio software as described previously (Benoist et al., 2013). To calculate spine/dendrite ratios of GluA1GFP and GluA2-GFP, total fluorescence intensity at each spine was measured and divided by the fluorescence intensity at the adjacent dendritic shaft. To quantify GluA1 and GluA2 surface versus total staining in primary neurons, regions of interest (ROIS) corresponding to individual dendrites from pyramidal neurons were delineated manually in the GFP channel. For each channel (surface or total staining), fluorescence intensities of three individual dendrites and the corresponding somas were then measured and averaged per neuron. To study GRIP1 distribution, ImageJ software was used for analysis. In the most prominent dendrite emanating from the soma, a $50 \mu \mathrm{m}$ segment was manually traced using signal from the GFP channel to determine morphology. The average 
A

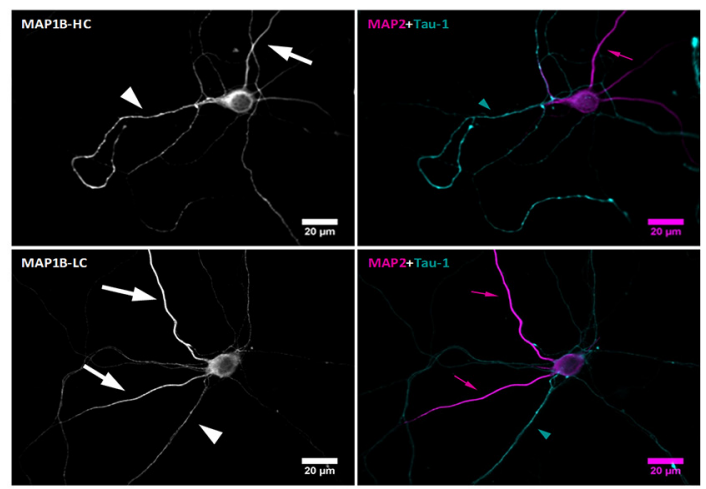

C

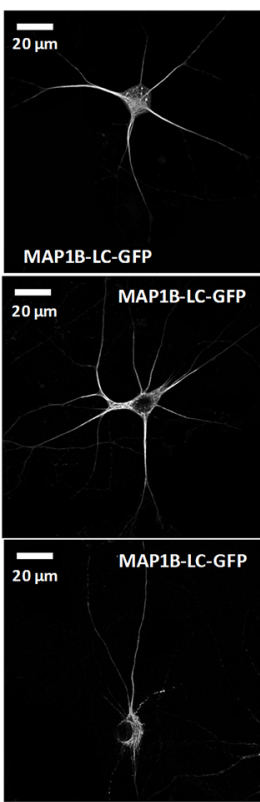

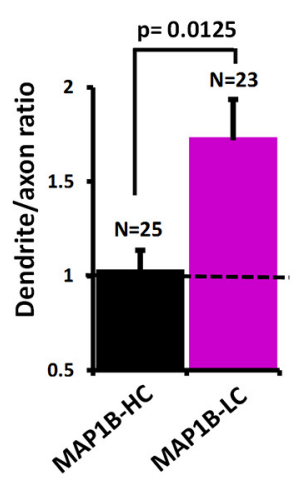
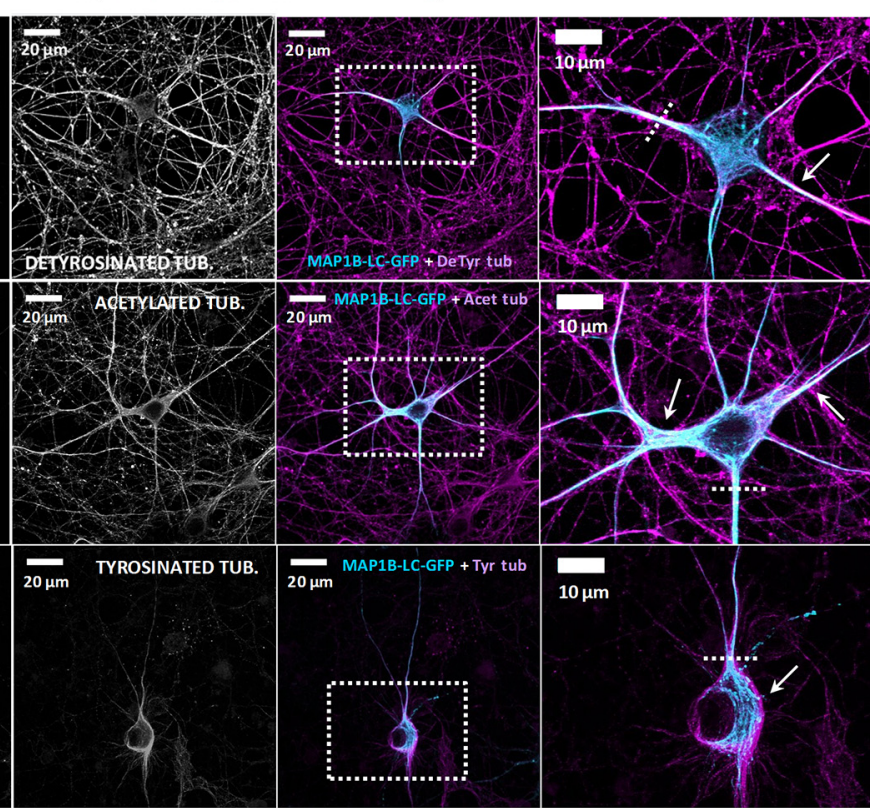

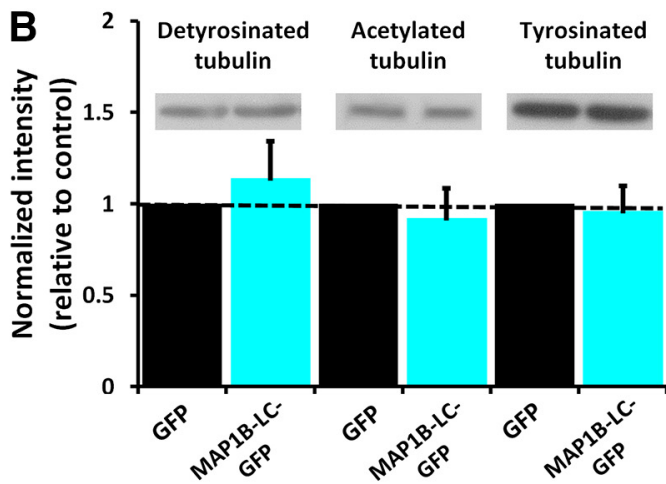

D
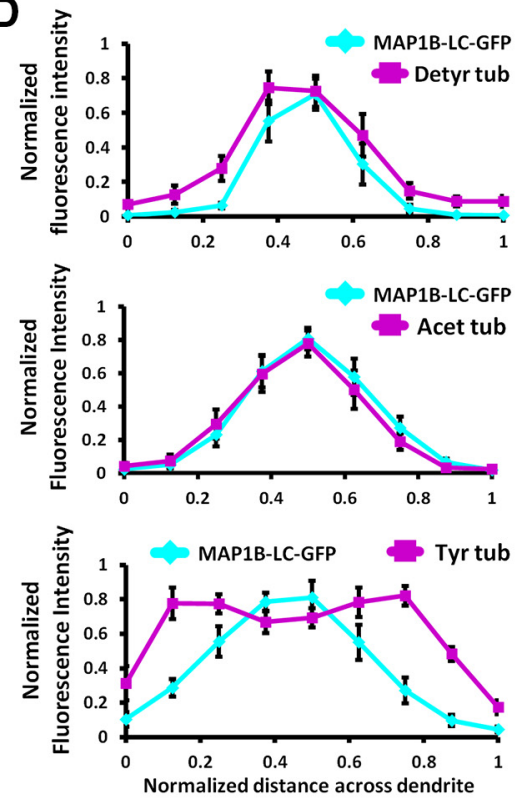

Figure 1. Subcellular distribution of MAP1B HC and LC in hippocampal neurons. $A$, Left, Representative images from primary hippocampal neurons after triple immunostaining against MAP1B-HC (left top) or MAP1B-LC (left bottom) together with MAP2 (somatodendritic marker) and Tau-1 (axonal marker) (magenta and cyan, respectively, in the merged right). Right, Quantification of the total immunostaining signal for MAP1B-HC or MAP1B-LC in the somatodendritic versus the axonal compartment from images as the one shown on the left. $N$ indicates the total number of cells. B, Top, Representative Western blots of detyrosinated, acetylated, and tyrosinated tubulin from organotypic hippocampal slices expressing either GFP or MAP1B-LC-GP. Bottom, Quantification of posttranslationally modified tubulin levels (normalized to actin) from $n=6$ (detyrosinated tubulin), $n=6$ (acetylated tubulin), and $n=7$ (tyrosinated tubulin) independent experiments. C, Left, MAP1B-LC-GFP expression in hippocampal primary neurons. Middle, Immunostaining against different posttranslational modifications of tubulin (detyrosinated, acetylated, and tyrosinated tubulin, as indicated). Right, Overlay and higher magnification of insets, with MAP1B-LC-GFP in blue and the corresponding tubulin immunostaining in magenta. Arrows indicate colocalization or exclusion of MAP1B-LC-GFP with each tubulin modification. White dashed lines in right-most panels indicate regions used for line plot quantifications. D, Line plots showing quantification of fluorescence intensity across several dendrites of neurons expressing MAP1B-LC-GFP (blue) and stained against detyrosinated, acetylated, and tyrosinated tubulin (magenta). Data are presented as the average distribution of normalized fluorescence intensity across dendrites of neurons stained for detyrosinated tubulin ( $n=6$ dendrites, $n=4$ neurons), acetylated tubulin ( $n=9$ dendrites, $n=7$ neurons), and tyrosinated tubulin ( $n=7$ dendrites, $n=5$ neurons).

fluorescence intensity for GRIP1 in this segment was measured and compared with the average fluorescence intensity in the cell body. Number, size, and fluorescence intensity of GRIP1 clusters were quantified with the Log3D plugin and ImageJ (Sage et al., 2005).

\section{Live imaging}

FRAP and photoconversion. Hippocampal organotypic slices previously infected or transfected to overexpress the proteins of interest were placed on a chamber perfused with ACSF gassed with $95 \% \mathrm{O}_{2} / 5 \% \mathrm{CO}_{2}$ and maintained at $37^{\circ} \mathrm{C}$. Images were acquired with a multiphoton microscope (Zeiss, LSM 510). For FRAP experiments, image acquisition and photobleaching were performed with $910 \mathrm{~nm}$ illumination. Maximumintensity projections were used for quantification. Total fluorescence intensity in the bleached area was normalized by the fluorescence in a nonbleached, adjacent region to compensate for ongoing photobleaching during image acquisition. In photoconversion experiments, the $405 \mathrm{~nm}$ laser was used to generate red fluorescence from recombinant proteins initially emitting in the green channel. Assessment of mobil- ity was based on monitoring red fluorescence over time after photoconversion.

TfR mobility. Primary neurons were either cotransfected with MAP1BLC-GFP (GFP as a control) and TfR-mCherry with lipofectamine for $48 \mathrm{~h}$ or infected with a lentivirus carrying a shRNA against MAP1B or scrambled control $8 \mathrm{~d}$ before transfection of TfR-GFP with lipofectamine. Coverslips of cultured neurons were assembled in a chamber filled with a specific buffer containing the following (in $\mathrm{mM}$ ): $146 \mathrm{NaCl}, 4.7 \mathrm{KCl}, 2.5$ $\mathrm{CaCl}_{2}, 0.6 \mathrm{MgSO}_{4}, 1.6 \mathrm{NaHCO}_{3}, 0.15 \mathrm{NaH}_{2} \mathrm{PO}_{4}, 8$ D-glucose, and 20 HEPES, pH 7.4. Time-lapse images were acquired in an inverted microscope Axiovert 200 microscope coupled to a CCD camera (Zeiss) every 2-3 s for $1 \mathrm{~min}$. Images were analyzed with the MultipleKymograph plugin for ImageJ submitted by J. Rietdorf and A. Seitz (European Molecular Biology Laboratory). Briefly, line type ROIs were drawn along dendrites of transfected neurons. For each frame of a time series, gray values along linear ROIs specified by hand drawing were read out using the MultipleKymograph plugin. From these lines of gray values, a new 
A

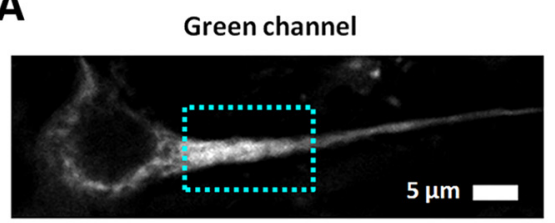

B
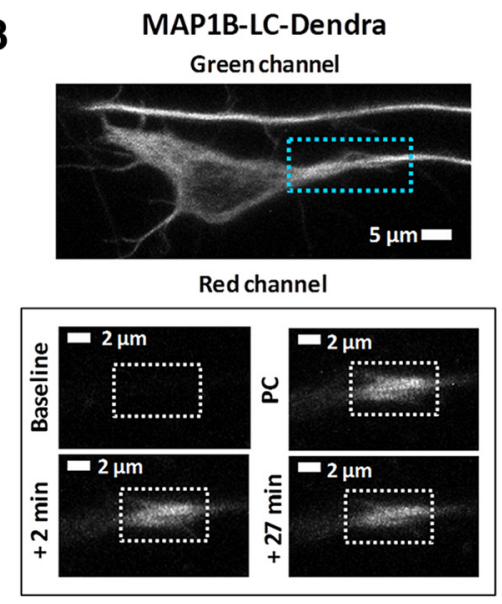

C
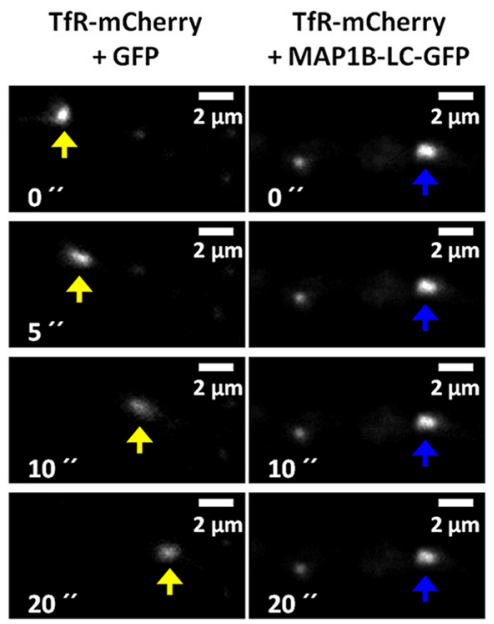
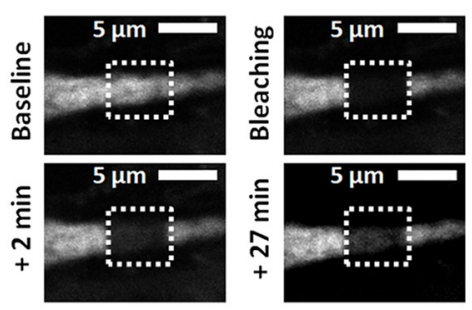

Dendra-tubulin Green channel

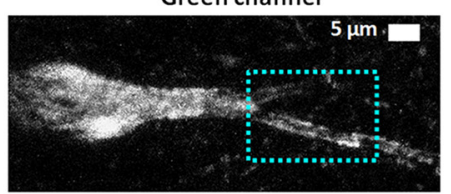

Red channel

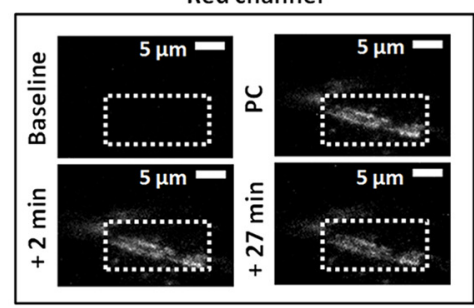

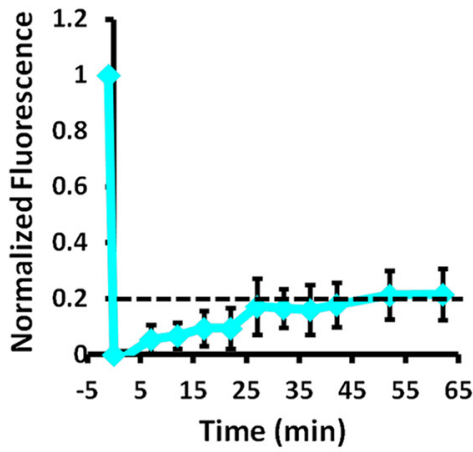

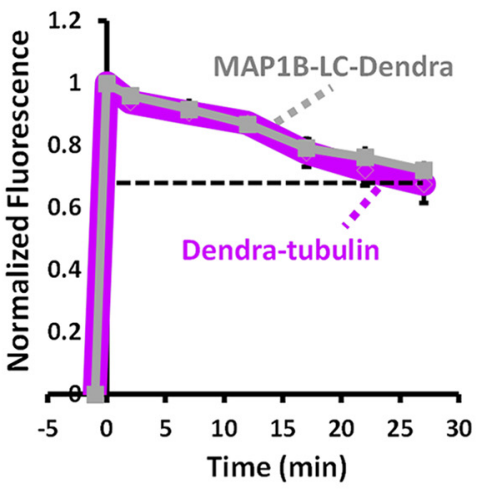

D $10 \mu \mathrm{m}$

TfR-GFP + shRNA TfR-GFP + against MAP1B scrambled shRNA
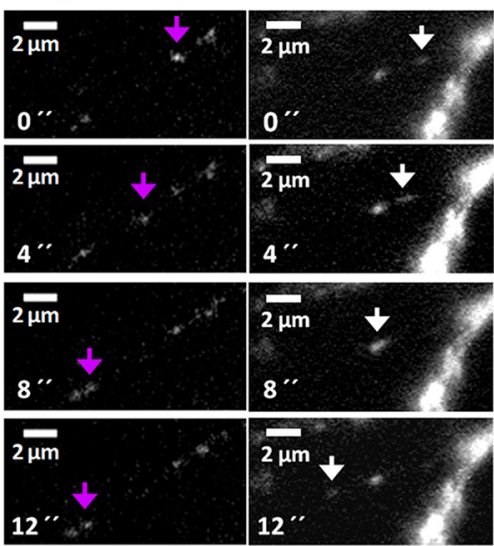

$\mathbf{F}$
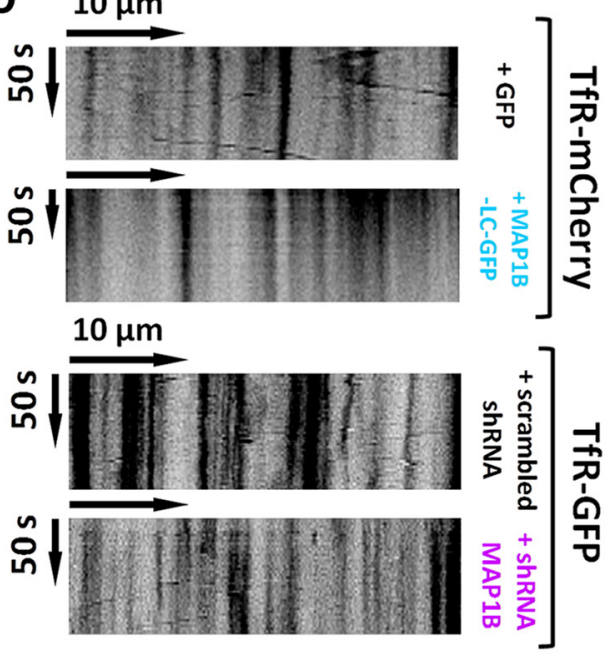

$\mathbf{E}$

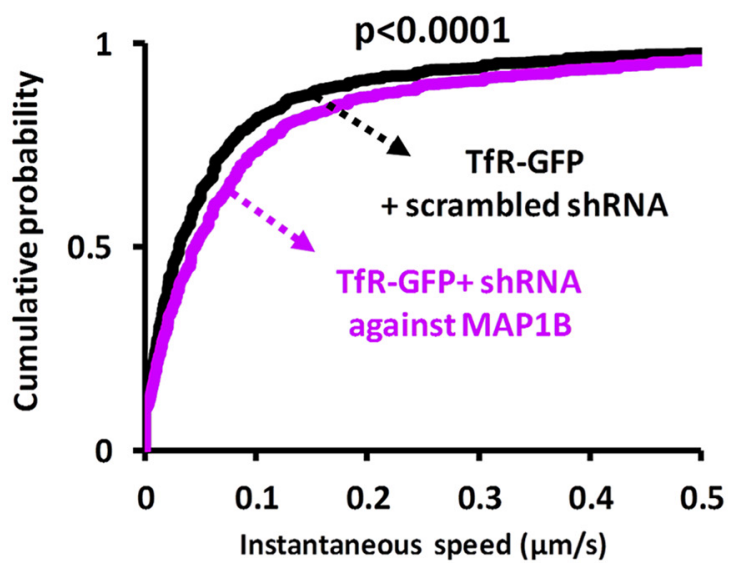

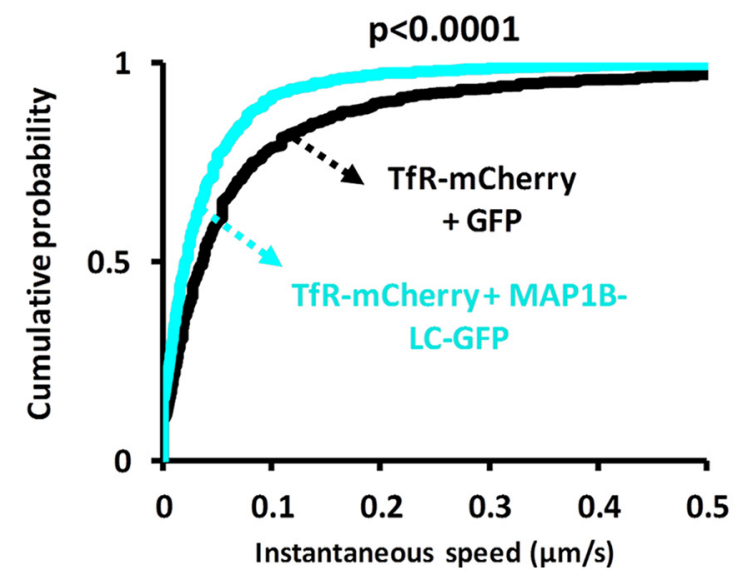

Figure 2. MAP1B-LC-GFP dynamics and effect on transferrin receptor transport in dendrites. A, Left, Representative images of a FRAP experiment performed on the dendrite of a hippocampal CA1 neuron expressing MAP1B-LC-GFP. The blue rectangle in the lower-magnification image represents the area magnified in the higher-magnification panels. The dashed white rectangle corresponds to the bleached area. Right, Quantification of three independent experiments shown as those on the left. $\boldsymbol{B}$, Left, representative images of a photoconversion (PC) (Figure legend continues.) 
image (the kymograph or time-space-plot) was assembled: the $y$-axis of the kymograph becomes a time axis (in seconds) and the $x$-axis is the distance (in $\mu \mathrm{m}$ ) along the line ROI. If a structure characterized by a certain intensity and contrast is moving along the ROI, it will appear as a contrast edge in the kymograph. Velocity (displacement per time interval) can then be measured by drawing a line type ROI along this edge. The angle of this line in the kymograph is proportional to the velocity.

\section{Statistical analyses}

All graphs represent average values \pm SEM. Statistical differences were calculated according to nonparametric tests. When comparing two conditions, $p$-values were calculated according to two-tailed Mann-Whitney tests (for unpaired data) or Wilcoxon tests (for paired data). Comparisons between cumulative distributions were calculated with the Kolmogorov-Smirnov test.

\section{Ethics statement}

All biosafety procedures and animal care protocols were approved by the bioethics committee from the Consejo Superior de Investigaciones Científicas (CSIC), and were performed according to the guidelines set out in the European Community Council Directives (86/609/EEC).

\section{Results}

MAP1B-LC is enriched in the somatodendritic compartment and associated with stable microtubules

It has been shown previously that MAP1B-LC exists in excess over its HC counterpart and may have separate functions from the HC/LC complex (Mei et al., 2000). To start exploring this possibility, we evaluated the enrichment of $\mathrm{HC}$ and LC in axonal and somatodendritic compartments in primary neuronal cultures. As shown in Figure $1 A$, MAP1B-HC was essentially equally represented in axonal (Tau1-positive; Fig. $1 A$, arrowheads) and somatodendritic (MAP2-positive; Fig. 1A, arrows) compartments. In contrast, MAP1B-LC was almost $75 \%$ more enriched in the somatodendritic compartment compared with the axonal one (Fig. 1A, quantification in right panel). These results support the notion that MAP1B-LC may have separate functions from MAP1B-HC, which may pertain specifically to the somatodendritic compartment.

To evaluate the subcellular localization of MAP1B-LC separately from the $\mathrm{HC}$, we performed immunofluorescence experiments on primary hippocampal neurons expressing MAP1B-LC tagged with GFP. The immunostaining was performed against three posttranslational modifications of tubulin: detyrosinated and acetylated tubulin, which are associated with stable microtubules (Kreis, 1987; Piperno et al., 1987; Schulze et al., 1987), and tyrosinated tubulin, which is considered to be a hallmark of dy-

\footnotetext{
$\leftarrow$

(Figure legend continued.) experiment performed on the dendrite of a hippocampal CA1 neuron expressing MAP1B-LC or tubulin tagged with Dendra2, as indicated. Blue and white rectangles are similar to $A$, but for photoconversion instead of photobleaching. Right, Quantification from experiments as the ones shown on the left, with Dendra2-Tubulin (magenta line, $n=4$ independent experiments) or with MAP1B-LC-Dendra2 (gray symbols, $n=8$ independent experiments). C, Left, Representative sequential pictures of TfR clusters imaged over time in dendrites of hippocampal primary neurons (9-10 din vitro, DIV) cotransfected with TfR-mCherry and MAP1B-LC-GFP (or GFP as control). Right, Similar to left panels after transfection with TfR-GFP and MAP1B shRNA (or scrambled shRNA as a control). D, Representative examples of kymographs generated from time-lapse images, as those shown in $\boldsymbol{C}$. , Cumulative distribution of the instantaneous speed of events of transport for TfR in neurons expressing MAP1B shRNA ( $N=2819$ events of transport, $n=4$ cells, $n=4$ independent experiments) or a scrambled shRNA ( $N=2125$ events, $n=4$ cells, $n=4$ independent experiments). $\boldsymbol{F}$, Cumulative distribution of the instantaneous speed of events of transport for TfR in primary neurons (DIV 9-10) coexpressing GFP (black) ( $N=2663$ events of transport, $n=3$ cells from $n=2$ independent experiments) or MAP1B-LC-GFP (cyan) ( $N=2943$ events, $n=3$ cells, $n=2$ independent experiments).
}

namic microtubules (Webster et al., 1987). First, we confirmed that overexpression of MAP1B-LC-GFP does not alter the extent of these tubulin modifications (Fig. $1 B$ ). Then, we found that MAP1B-LC-GFP colocalizes with detyrosinated and acetylated (stable) tubulin (Fig. 1C, top and center), but not with tyrosinated (dynamic) tubulin (Fig. $1 C$, bottom). Fluorescence line plots from multiple dendrites illustrate the spatial coincidence of MAP1B-LC-GFP with detyrosinated and acetylated tubulin and an exclusion pattern with tyrosinated tubulin (Fig. 1D).

\section{MAP1B-LC forms immobile complexes and limits vesicular trafficking along dendrites}

To explore the dynamics of MAP1B-LC in dendritic compartments, we characterized the mobility of MAP1B-LC-GFP inside CA1 pyramidal neurons from organotypic hippocampal slices, using fluorescence recovery after photobleaching (FRAP) and photoconversion experiments. As shown in Figure $2 A$, only a $20 \%$ fraction of the initial GFP fluorescence was recovered after $>1$ h from the photobleaching event, indicating that MAP1B-LCGFP is mostly anchored inside the dendritic shaft. As a complementary approach, we performed photoconversion experiments in CA1 neurons expressing MAP1B-LC fused to the green-to-red photoconvertible protein Dendra (Gurskaya et al., 2006). As shown in Figure 2B, 70-80\% MAP1B-LC-Dendra remained immobile after photoconversion in the dendritic shaft, in agreement with the FRAP experiments. We then performed similar experiments with Dendra-tubulin to assess the stability of microtubules with this assay. As shown in Figure $2 B$, the photoconversion dynamics of Dendra-tubulin was very slow and similar to that of MAP1B-LC, with virtually overlapping curves of fluorescence decay over time. Therefore, these live imaging experiments show that MAP1B-LC is strongly immobile and suggest that it behaves very similarly to stable microtubules, strengthening the notion that MAP1B-LC is forming a protein complex with microtubules in dendritic compartments.

Because MAP1B-LC forms immobile complexes on microtubules, we tested whether MAP1B expression levels may modulate the efficiency of vesicular transport in dendrites. To this end, we analyzed the transport of GFP- or mCherry-tagged TfRs along dendrites of hippocampal primary neurons upon decreasing (shRNA knockdown) or increasing (overexpression) MAP1B-LC levels. The effectiveness of the shRNA at downregulating MAP1B-LC was estimated at $\sim 50 \%$ (Benoist et al., 2013), but it should be noted that this knockdown of MAP1B mRNA will necessarily affect both light and heavy chains. Conversely, MAP1B-LC overexpression is specific for the LC and was estimated to be $\sim 10$ fold, as quantified by immunocytochemistry on primary neurons comparing anti-MAP1B-LC signal in infected and noninfected cells (results not shown). The movement of TfR-GFP or TfRmCherry clusters along dendrites was monitored by time-lapse imaging (Fig. 2C) and quantified using kymographs (Fig. 2D). As shown in Figure 2E, the transport of TfR-GFP clusters was accelerated upon downregulation of endogenous MAP1B in neurons (right shift in the cumulative distribution of instantaneous speed). Conversely, TfR-mCherry clusters moved significantly slower in the presence of overexpressed MAP1B-LC-GFP (Fig. $2 F$; left shift in the cumulative distribution of instantaneous speed). These effects were similar on anterograde and retrograde transport events (not shown).

Therefore, these results demonstrate a bidirectional modulation of microtubule-dependent vesicular transport by the expression levels of MAP1B. Importantly, these data also imply that, 

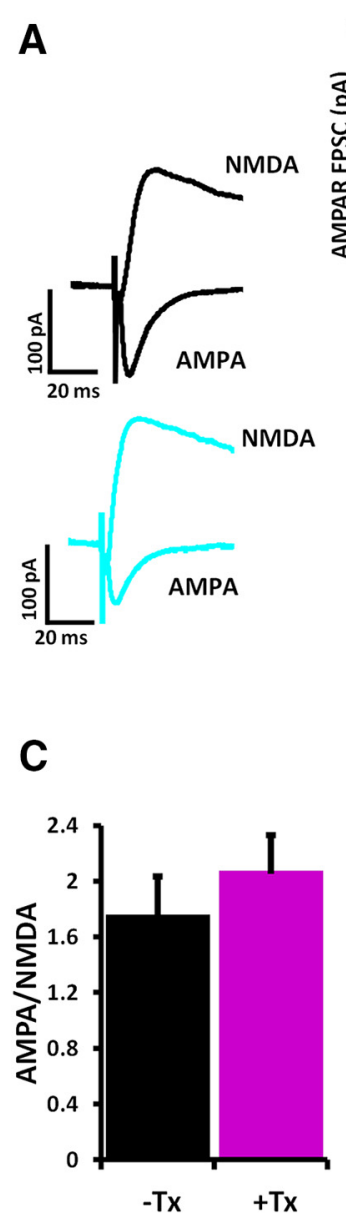
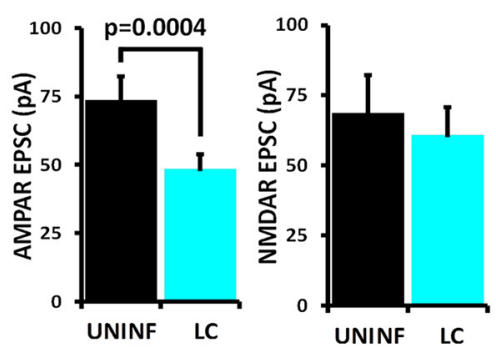

B
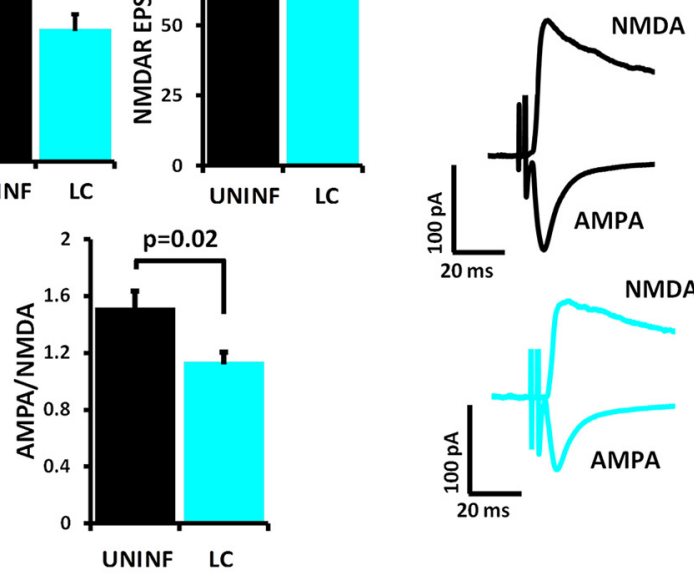

D

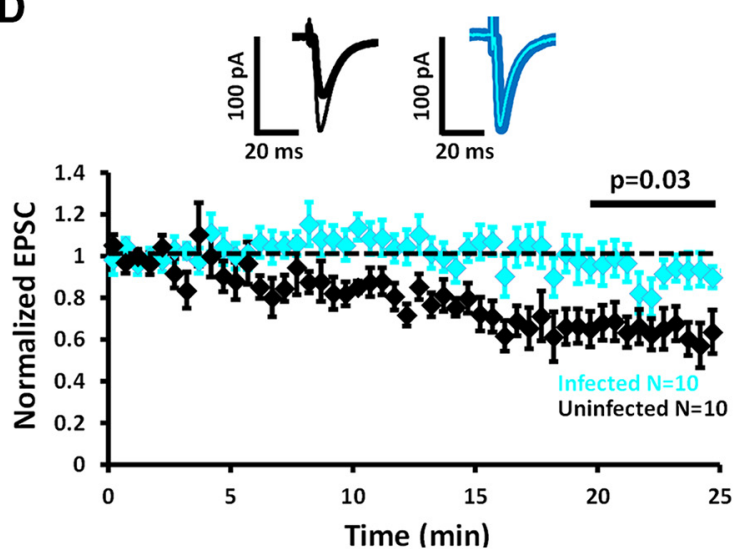

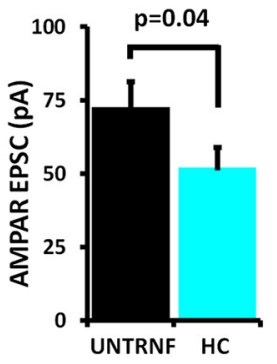
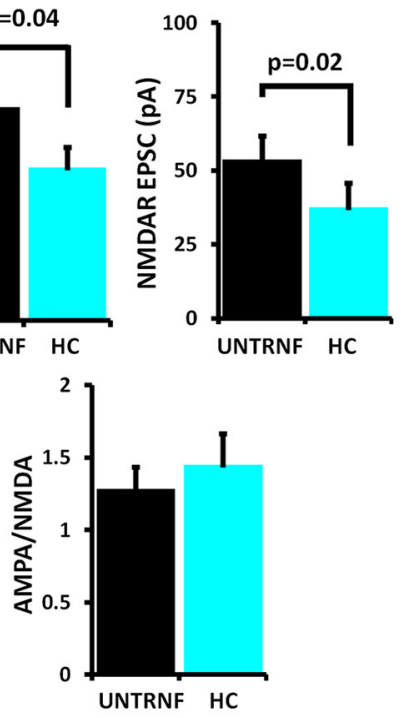

E
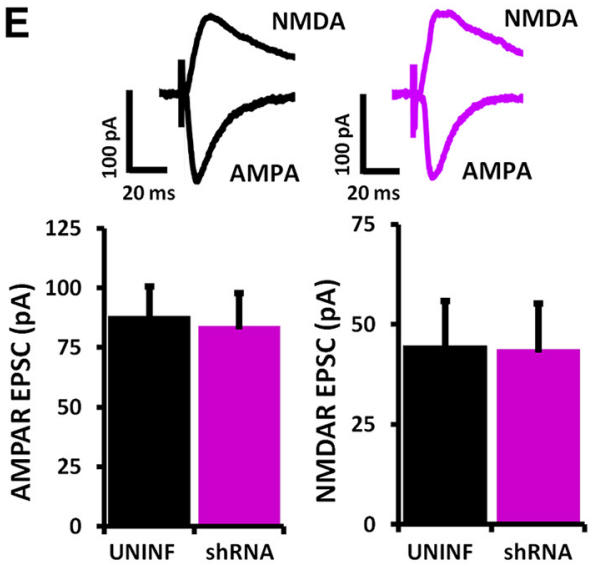

Figure 3. Effect of MAP1B-LC-GFP expression on basal synaptic transmission. $A$, Synaptic responses were recorded from pairs of neighboring CA1 neurons overexpressing MAP1B-LC-GFP (LC, blue columns) and control neurons (uninfected, UNINF, black columns) in the presence of picrotoxin at $-60 \mathrm{mV}$ for AMPARs ( $n=42$ pairs) and at $+40 \mathrm{mV}$ for NMDARs ( $n=29$ pairs). AMPA and NMDA responses from individual cells are also used to calculate AMPA/NMDA ratios (bottom). Representative traces are shown on the left (blue traces for infected neurons). $\boldsymbol{B}$, Similarly, synaptic responses were recorded from pairs of neighboring CA1 neurons overexpressing MAP1B-HC-GFP (HC, blue columns) and control neurons (untransfected, UNTRNF, black columns), in the presence of picrotoxin at $-60 \mathrm{mV}$ for AMPARs ( $n=23$ pairs) and at $+40 \mathrm{mV}$ for NMDARs ( $n=14$ pairs). AMPA and NMDA responses from individual cells were used to calculate AMPA/NMDA ratios (lower). Representative traces are shown on the left (blue traces for transfected neurons). C, Average value of AMPA/NMDA ratio for neurons from hippocampal slices treated with either $10 \mathrm{~nm}$ taxol (+ TX, $n=18$ cells) or $0.01 \%$ DMSO ( $-\mathrm{TX}, n=23$ cells) for a period of $3-6 \mathrm{~h}$. D, Time course of AMPAR EPSCs recorded in patch-clamp configuration at $-60 \mathrm{mV}$ in the presence of picrotoxin during the infusion of pep $2 \mathrm{~m}$ (included in patch pipette) in neurons overexpressing MAP1B-LC-GFP (blue symbols) and control neurons (black symbols). $p$-value is derived from the average response between 20 and 25 min of recording. Nindicates the number of cells. Sample traces for uninfected and infected cells are shown above the plot. $E$, Synaptic responses were recorded from pairs of neighboring CA1 neurons expressing an shRNA against MAP1B (shRNA) and control neurons (uninfected, UNINF) in the presence of picrotoxin at $-60 \mathrm{mV}$ for AMPARs ( $n=21 \mathrm{pairs}$ ) and at $+40 \mathrm{mV}$ for NMDARs ( $n=13$ pairs). Representative traces are shown above (magenta traces for shRNA expressing neurons).

under basal conditions, vesicular transport along dendrites is limited by the endogenous levels of MAP1B.

Increasing MAP1B-LC expression impairs AMPAR-mediated synaptic transmission

To start exploring the functional consequences of MAP1B-LC's regulation of vesicular trafficking, we first tested whether expression of MAP1B-LC alters basal synaptic transmission. To this end, we overexpressed MAP1B-LC-GFP in CA1 pyramidal neurons and measured AMPAR- and NMDAR-dependent synaptic currents. As shown in Figure 3A, MAP1B-LC overexpression was accompanied by a significant decrease in AMPAR-mediated synaptic currents, whereas NMDAR-dependent transmission was unaltered. Accordingly, MAP1B-LC overexpression produced a significant decrease in the ratio of AMPA-to-NMDA responses (Fig. $3 A$, right). To test the specificity of this effect, we performed similar experiments overexpressing MAP1B-HC. In this case, we observed significant depression of both AMPAR- and NMDARmediated synaptic responses, with no net change in the AMPA-toNMDA ratio (Fig. 3B). Given this general effect of MAP1B-HC on synaptic transmission, we did not explore it any further and focused instead on the specific effects of MAP1B-LC on AMPARs. MAP1B-LC has been shown to enhance microtubule stability (Noiges et al., 2002). Nevertheless, the specific effect of MAP1B-LC on AMPAR synaptic transmission is not simply due to microtubule stabilization because incubation of organotypic hippocampal slices with the microtubule-stabilizing agent taxol (10 nM, 3-6 h) did not alter the ratio between AMPAR and NMDAR responses compared with vehicle (DMSO)-treated slices (Fig. 3C).

The maintenance of synaptic transmission under basal conditions is thought to depend on the continuous cycling of AMPARs in and out of synapses (Lüscher et al., 1999). This constitutive turnover depends on the interaction between N-ethylmaleimidesensitive fusion protein (NSF) and the C terminus of the GluA2 
subunit and can be disengaged with a small peptide mimicking the NSF-binding site of GluA2 ("pep2m") (Nishimune et al., 1998; Song et al., 1998; Lüscher et al., 1999; Noel et al., 1999). To test whether MAP1B-LC participates in this process, we recorded AMPAR-dependent basal transmission in CA1 neurons overexpressing MAP1B-LC-GFP and in uninfected, control neurons while infusing pep $2 \mathrm{~m}$ with the internal solution contained in the patch pipette. As shown in Figure 3D, a decrease of AMPARmediated synaptic transmission was observed in uninfected neurons, reflecting the removal of AMPARs that failed to be reinserted at synapses. In contrast, synaptic transmission was stable over time in MAP1B-LC-GFP-overexpressing CA1 neurons. This result indicates that the population of NSF-dependent cycling AMPARs is reduced (or absent) in MAP1B-LC-overexpressing neurons. Finally, we used shRNA-mediated knockdown to determine whether reducing MAP1B-LC levels might have an opposite effect to MAP1B-LC overexpression on AMPAR responses. This approach will downregulate both MAP1B-LC and MAP1B-HC because these proteins are generated by proteolytic cleavage from full-length MAP1B. As shown in Figure 3E, downregulation of MAP1B did not alter AMPAR- or NMDAR-mediated synaptic responses. This result indicates that the modulation of AMPARs by MAP1B-LC is not bidirectional because reducing MAP1B-LC (together with MAP1B-HC) is not sufficient to increase synaptic transmission.

\section{MAP1B-LC impairs spine targeting of a subunit-specific population of AMPARs}

MAP1B is required for proper dendritic spine development and maturation through the modulation of small GTPase activity (Tortosa et al., 2011). MAP1B has also been shown to affect synaptic structure (Bodaleo et al., 2016). Therefore, we first tested whether the decrease in AMPAR-dependent transmission by MAP1B-LC overexpression is the consequence of altered dendritic spine morphology. Using morphometric analysis of biocytin-filled neurons (Fig. $4 A$ ), we did not detect any significant difference in spine head diameter, length, or density between neurons overexpressing MAP1B-LC and control neurons (Fig. 4B). Therefore, the decreased basal transmission observed upon MAP1B-LC overexpression could not be explained by an alteration in number or size of dendritic spines. In addition, no difference in the activity of small GTPases Racl or RhoA (known regulators of the actin cytoskeleton) was found in organotypic slices overexpressing MAP1B-LC-GFP versus GFP-expressing, control slices (results not shown).

We next tested whether MAP1B-LC was altering the trafficking of AMPARs from dendritic compartments to spines. The GluA2-GluA3 population of AMPARs has been shown to cycle in and out of the synaptic membrane independently from neuronal activity and, in this manner, may be responsible for the maintenance of basal synaptic transmission (Passafaro et al., 2001; Shi et al., 2001). Homomeric GluA2 receptors have been shown to traffic to synapses constitutively and thus serve to monitor the cycling population of AMPARs (Shi et al., 2001). We analyzed GluA2 accumulation in dendritic spines in the presence or absence of MAP1B-LC-GFP. We coexpressed RFP-GluA2 together with MAP1B-LC-GFP or GFP as a control in organotypic hippocampal slices via biolistic transfection. As shown in Figure 4C, left, the accumulation of GluA2-RFP in dendritic spines is strongly reduced when coexpressed with MAP1B-LC-GFP compared with GFP-expressing neurons. This is reflected as a left shift in the cumulative distribution of spine/dendrite ratios in neurons overexpressing MAP1B-LC-GFP versus the GFP condition (Fig. 4D, gray and magenta curves; see also mean spine/dendrite values in Fig. 4E).

A similar experiment was performed with the GluA1 subunit of AMPARs together with a constitutively active form of CaMKII (tCaMKII) to drive GluAl homomers into dendritic spines (Hayashi et al., 2000) (Fig. 4C, right). Cumulative distributions of spine/dendrite ratios for GluA1 in the presence of MAP1B-LC-mCherry or mCherry alone were basically overlapping (Fig. $4 D$, blue and black curves) and there was no difference in the average spine/dendrite value (Fig. 4E). These results indicate that MAP1B-LC specifically impairs the dendrite-to-spine constitutive trafficking of GluA2 AMPARs, but not the regulated (CaMKII-dependent) transport of GluA1-containing AMPARs.

Together, these data demonstrate that MAP1B-LC modulates the trafficking of a specific population of AMPARs: those constitutively cycling in and out of the synaptic membrane of dendritic spines. In this manner, MAP1B-LC expression affects basal synaptic transmission directly.

\section{LTP is enhanced in MAP1B-LC-overexpressing neurons}

MAP1B has been implicated in the regulated endocytosis of AMPARs during NMDAR- and mGluR-dependent LTD (Davidkova and Carroll, 2007; Benoist et al., 2013). Therefore, we assessed whether overexpression of MAP1B-LC may have an effect on synaptic plasticity. NMDAR-dependent LTD was induced by pairing presynaptic stimulation (300 pulses at $1 \mathrm{~Hz}$ ) with mild postsynaptic depolarization $(-40 \mathrm{mV})$. As shown in Figure 5A, AMPARmediated synaptic responses were equally depressed in MAP1B-LCoverexpressing and control neurons. Similarly, there was no difference in mGluR-dependent LTD induced by DHPG infusion in infected cells versus noninfected cells (Fig. 5B).

We then tested whether MAP1B-LC may have an effect on LTP expression. We induced LTP in neurons overexpressing MAP1B-LC-GFP and control neurons by pairing presynaptic stimulation $(3 \mathrm{~Hz})$ with postsynaptic depolarization $(0 \mathrm{mV})$. A twofold potentiation was observed in uninfected neurons (Fig. $5 C$ ). In contrast, synaptic potentiation was significantly higher in MAP1B-LC-overexpressing neurons, approximately fourfold. This is likely the consequence of the reduced AMPAR-dependent basal transmission in these neurons. Therefore, a normal insertion of AMPARs during LTP would produce a larger relative potentiation if basal transmission were initially depressed. This effect has been observed previously when interfering with GluA2depending trafficking (Shi et al., 2001) or in the GluA2 knock-out mouse (Jia et al., 1996). Therefore, the enhanced LTP that we observed in MAP1B-LC-overexpressing neurons is consistent with the interpretation that MAP1B-LC interferes specifically with constitutive GluA2-dependent trafficking.

A specific impairment of GluA2 trafficking may give rise to the appearance of GluA2-lacking receptors at synapses, which would also have consequences for LTP expression because of their calcium permeability (Jia et al., 1996). To evaluate whether this was the case, we measured the rectification index of AMPAR-mediated synaptic transmission in MAP1B-LC-overexpressing neurons. As shown in Figure 5D, MAP1B-LC overexpression did not affect rectification, indicating that synaptic transmission is still mediated by GluA2-containing AMPARs.

\section{MAP1B-LC reduces the mobile fraction of GluA2 AMPARs in dendrites}

To elucidate how MAP1B-LC impairs the insertion of AMPARs into dendritic spines and the synaptic membrane, we evaluated the effect of MAP1B-LC in AMPAR dynamics. We coexpressed 
A
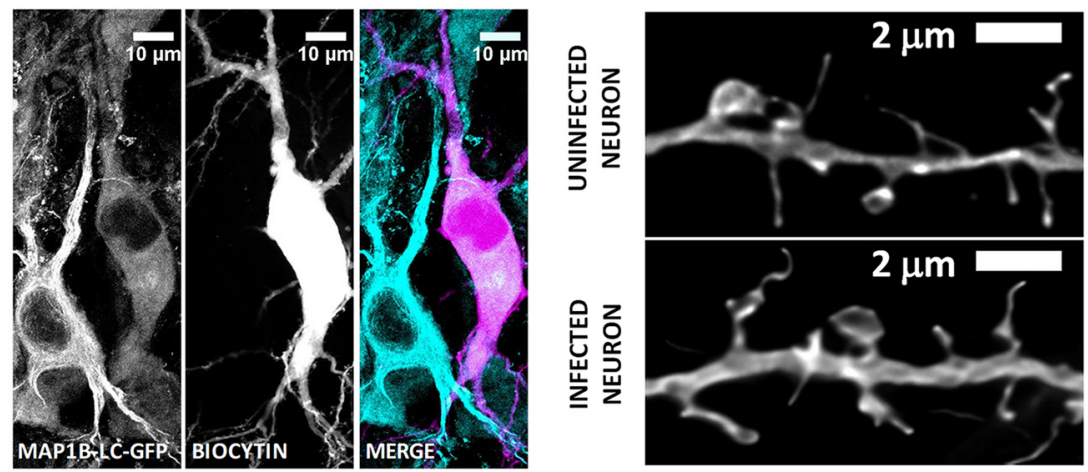

B
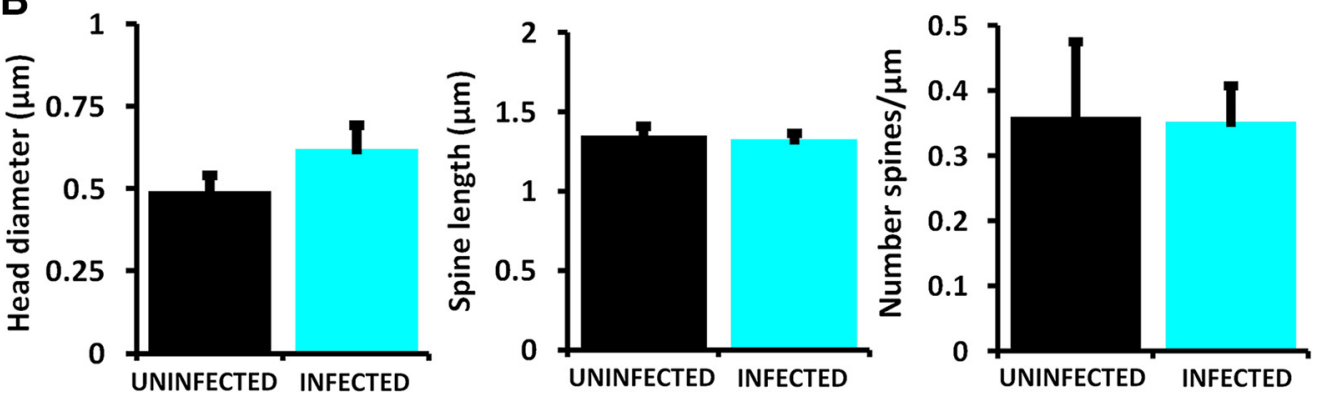

C

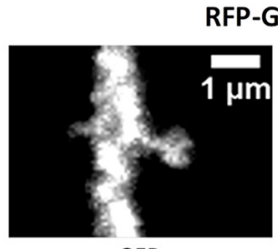

GFP

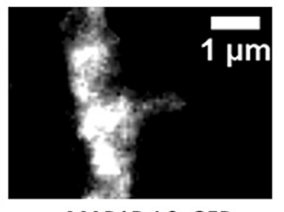

MAP1B-LC -GFP

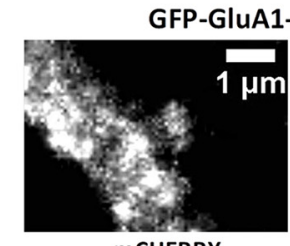

mCHERRY

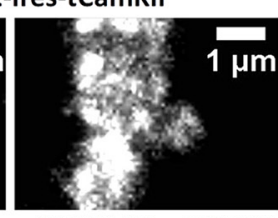

MAP1B-LC -mCHERRY

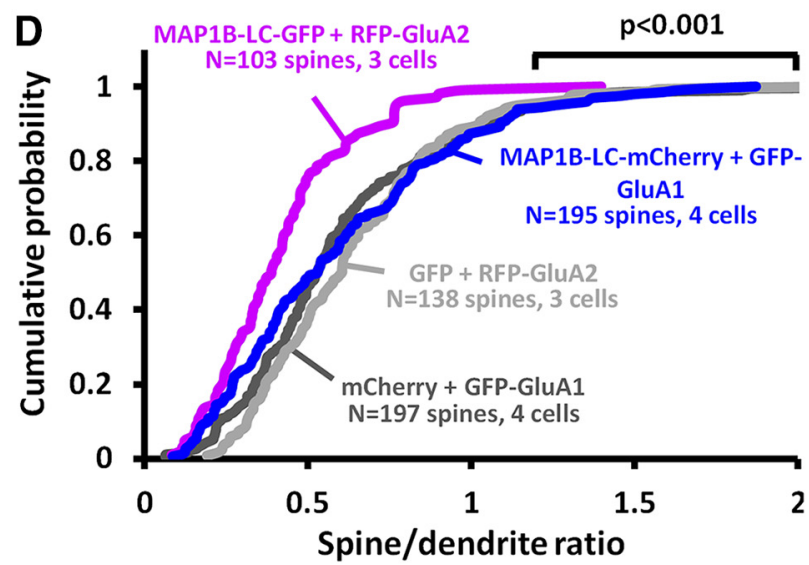

E

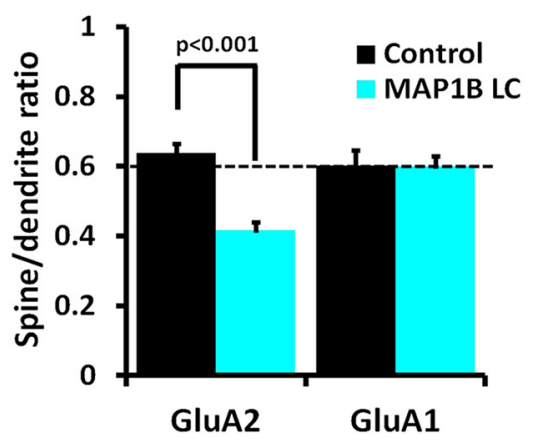

Figure 4. Effect of MAP1B-LC-GFP expression on spine morphology and AMPAR spine localization. $A$, Left, Representative image of CA1 neurons overexpressing MAP1B-LC-GFP (blue, in the merged) with one of them filled with biocytin (magenta in the merged). Right, Representative confocal deconvoluted images of dendritic spines in apical dendrites of uninfected, control CA1 neurons and infected neurons overexpressing MAP1B-LC-GFP. B, Quantification of average head diameter, spine length, and spine density in uninfected $(n=5)$ and infected $(n=4)$ neurons. $\boldsymbol{C}$, Left, Representative confocal images of dendritic spines from neurons coexpressing RFP-GluA2 and MAP1B-LC-GFP or GFP as a control. Right, Representative confocal images of GFP-GluA1 in dendritic spines of neurons coexpressing MAP1B-LC-mCherry or mCherry as a control. GluA1 is coexpressed with a constitutively active form of CaMKII (tCaMKII) by means of an IRES. D, Quantification of fluorescence intensity in spines versus adjacent dendrite from neurons like those in $\boldsymbol{C}$. Data are presented as cumulative distributions of spine/dendrite ratios. $\boldsymbol{E}$, Average spine/dendrite ratio for recombinant GluA2 and GluA1 in the presence of overexpressed MAP1B-LC or in control conditions. p-value was obtained according to the total number of quantified dendritic spines per condition.

GFP-GluA2 with either MAP1B-LC-mCherry or mCherry as a control in organotypic hippocampal slices. The mobility of GluA2 homomers at dendritic spines was then assessed using FRAP experiments (Fig. 6A, top). We monitored fluorescence recovery of GFP-GluA2 at spines over a period of time of $30 \mathrm{~min}$. To our surprise, the same recovery profile was obtained for cells expressing either MAP1B-LC-mCherry or mCherry alone (Fig. 6A, bot- tom). Therefore, despite the reduced accumulation of GluA2 in dendritic spines, the dynamics of this pool of receptors appeared to be normal in the presence of increased levels of the LC of MAP1B.

To further understand the effect of MAP1B-LC in the dynamics of AMPARs, we tested the mobility of GluA2 subunits in dendrites. Photobleaching of GFP-GluA2 was performed on the dendritic 



Figure 5. Effect of MAP1B-LC-GFP expression on synaptic plasticity. AMPAR-mediated synaptic responses were recorded from CA1 neurons and normalized to the average baseline value before the induction of plasticity. $A$, Left, Time course of NMDAR-dependent LTD ( 300 pulses at $1 \mathrm{~Hz}$, depolarization at $-40 \mathrm{mV}$ ) in control neurons and neurons overexpressing MAP1B-LC-GFP, with representative traces above. Right, Average responses collected from the last $5 \mathrm{~min}$ of the recording and normalized to the baseline. Left columns (paired) correspond to the induced pathway. Right columns (unpaired) correspond to the pathway that was not stimulated during the induction. B, Left, mGluR-LTD was induced with $50 \mu \mathrm{m}$ of (RS)-3,5-DHPG for 5 min, as indicated with the black bar. Representative traces are shown above. Right, Average responses collected from the last $5 \mathrm{~min}$ of the recording and normalized to the baseline. $\boldsymbol{C}$, Top, Time course of LTP ( 300 pulses at $3 \mathrm{~Hz}$, depolarization at $0 \mathrm{mV}$ ) for control neurons and neurons overexpressing MAP1B-LC-GFP. Bottom, Average responses collected from the last 5 min of the recording and normalized to the baseline. Left columns (paired) correspond to the induced pathway. p-value on top of the graph corresponds to the statistical significance comparing the extent of potentiation in uninfected versus infected neurons (Mann-Whitney test). Right columns (unpaired) correspond to the pathway that was not stimulated during the induction. Representative traces are shown on the right. For all panels, $p$-values shown above columns correspond to the statistical significance of synaptic depression $(\boldsymbol{A}, \boldsymbol{B})$ or potentiation $(\boldsymbol{C})$, according to the Wilcoxon test. Nindicates the number of cells. $\boldsymbol{D}$, Rectification index of CA1 control neurons (uninfected, $n=10$ cells) and neurons overexpressing MAP1B-LC-GFP (infected, $n=10$ cells), with representative traces shown above. AMPAR-mediated responses were recorded at $-60 \mathrm{mV}$ and $+40 \mathrm{mV}$ in the presence of spermine. The rectification index was calculated as the ratio of AMPAR-mediated synaptic responses at both holding potentials. 
A
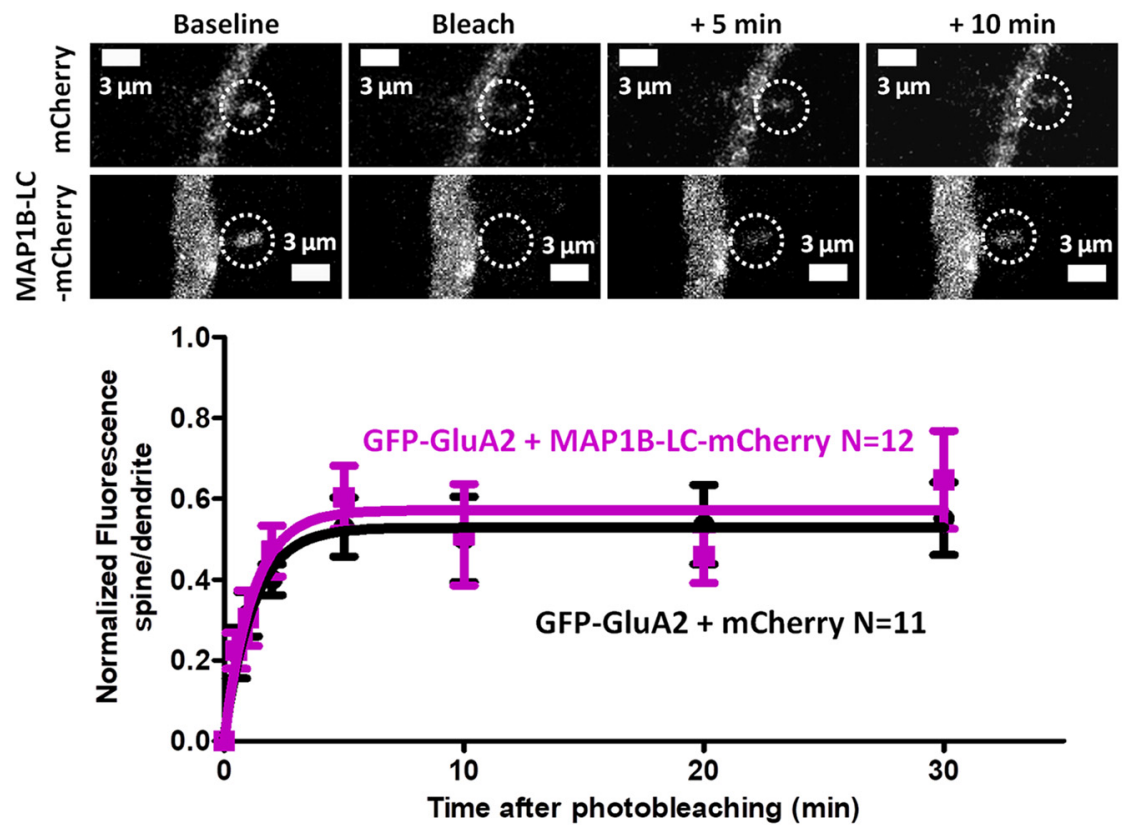

B
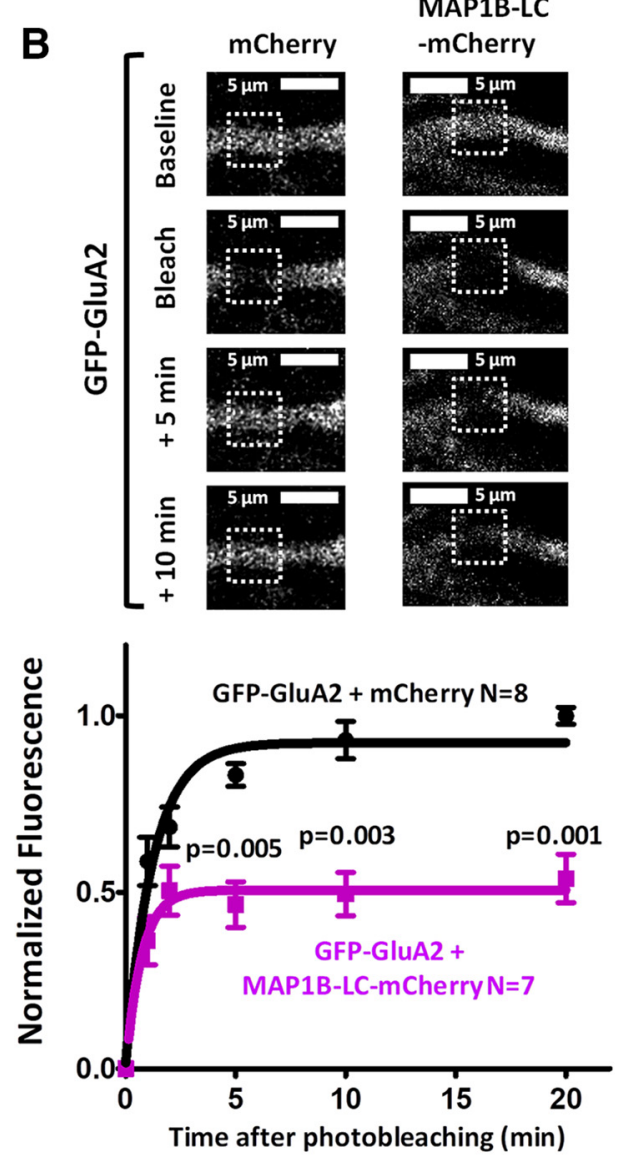

C

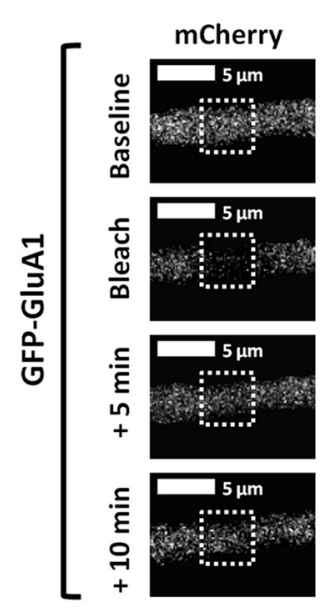

MAP1B-LC

-mCherry
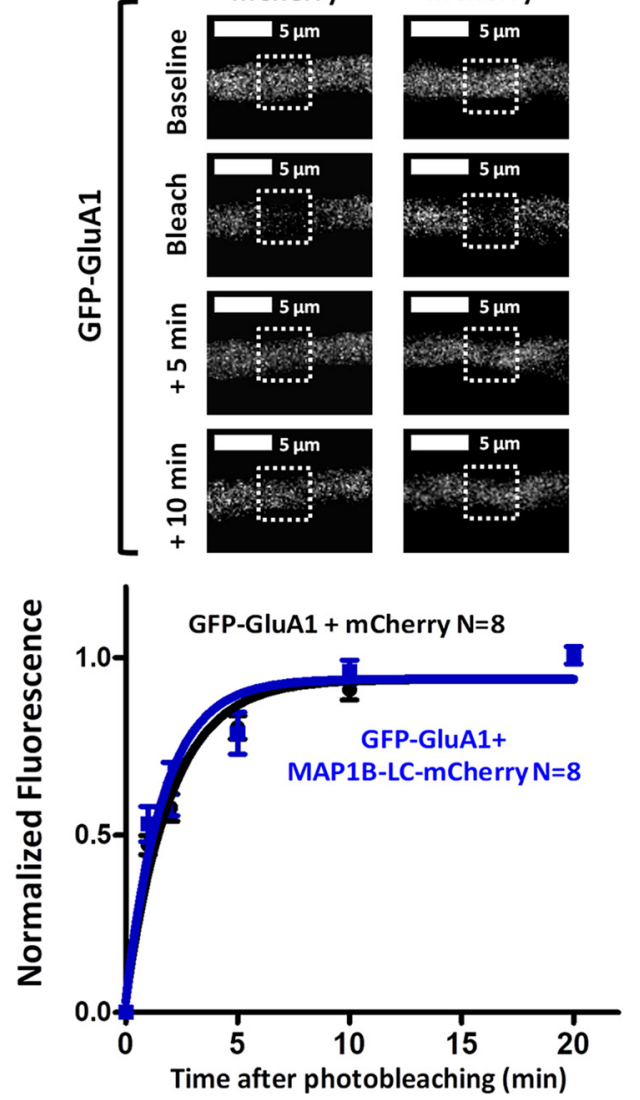

Figure 6. Differential effect of MAP1B-LC expression on GFP-GluA1 and -GluA2 dynamics at spines and dendritic shafts. A, Top, Representative two-photon images of GFP-GluA2 at spines of neurons expressing either mCherry or MAP1B-LC-mCherry during a FRAP experiment. Images were acquired before photobleaching ("baseline"), immediately after photobleaching ("bleach") and at the indicated times during fluorescence recovery. Bleached regions are indicated with dashed circles. Bottom, Quantification of GFP-GluA2 fluorescence at the spine normalized to the baseline value before photobleaching. Fluorescence intensity at the spine is normalized to the adjacent dendritic shaft (spine/dendrite ratio) to compensate for ongoing photobleaching during image acquisition. Time courses obtained in both conditions were fitted to single exponentials. N indicates the number of spines. $\boldsymbol{B}$, Top, Representative two-photon images of GFP-GluA2 at dendritic branches of neurons expressing either mCherry or MAP1B-LC-mCherry during a FRAP experiment. Images were acquired before photobleaching ("baseline"), immediately after photobleaching ("bleach"), and at the indicated times during fluorescence recovery. Bleached regions are indicated with dashed squares. Bottom, Quantification of GFP-GluA2 fluorescence at the dendrite normalized to the baseline value before photobleaching. Fluorescence intensity at the bleached area is normalized to a reference, "nonbleached" region of the dendrite to compensate for ongoing photobleaching during image acquisition. Time courses in both conditions were fitted to single exponentials. $N$ indicates the number of dendrites. $\boldsymbol{C}$, Same experiment as in $\boldsymbol{B}$, but coexpressing GFP-GluA1 with either mCherry or MAP1B-LC-mCherry instead of GFP-GluA2. 
A

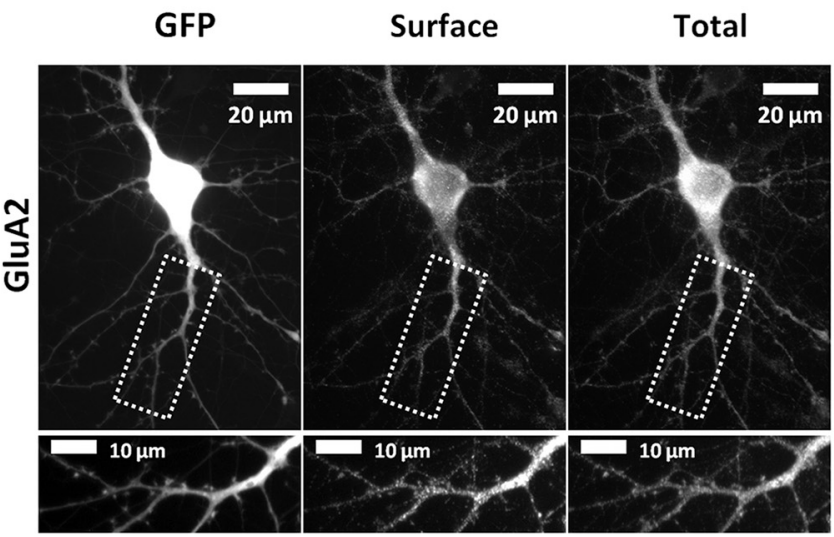

B

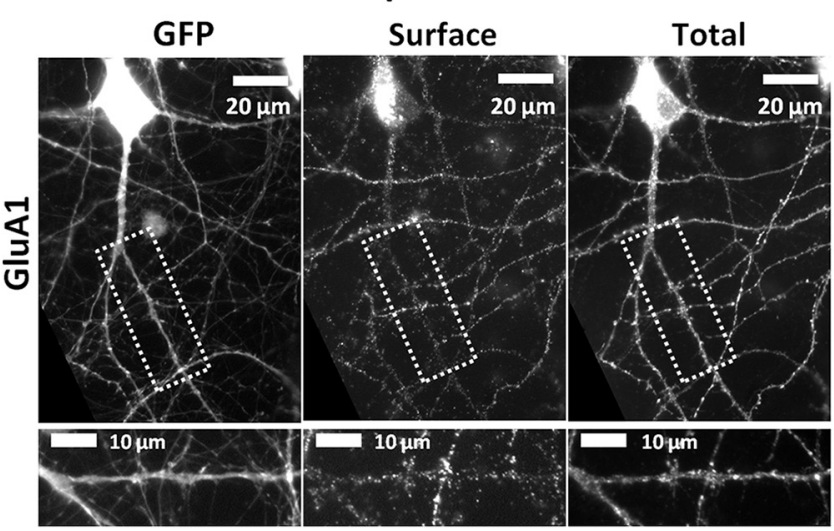

Over-expression of MAP1B-LC-GFP

GFP

Surface

Total

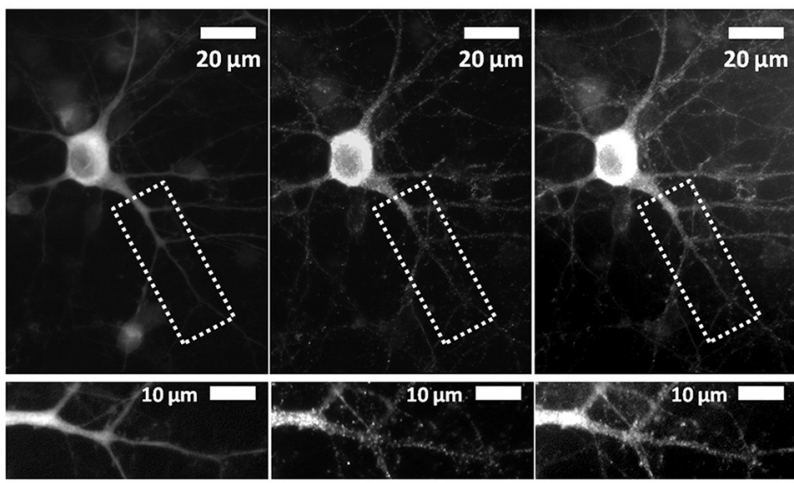

Over-expression of MAP1B-LC-GFP

GFP

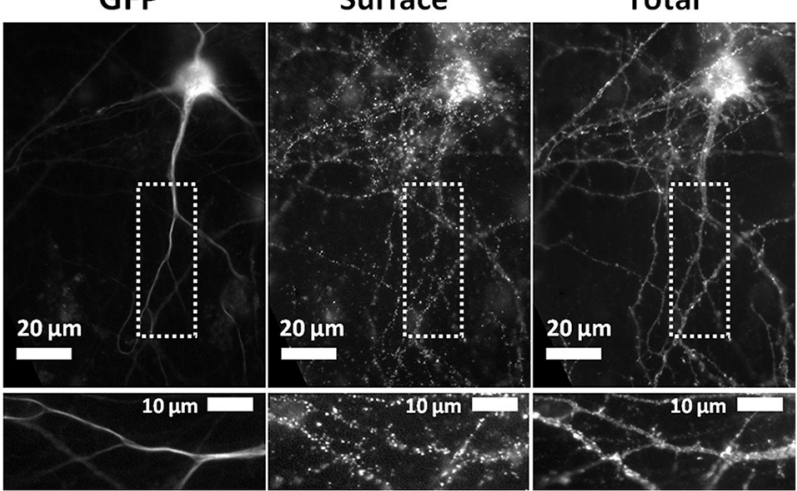

C

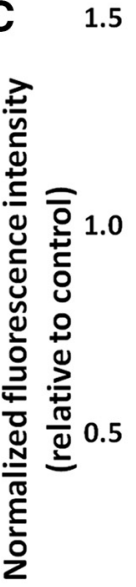

0.0
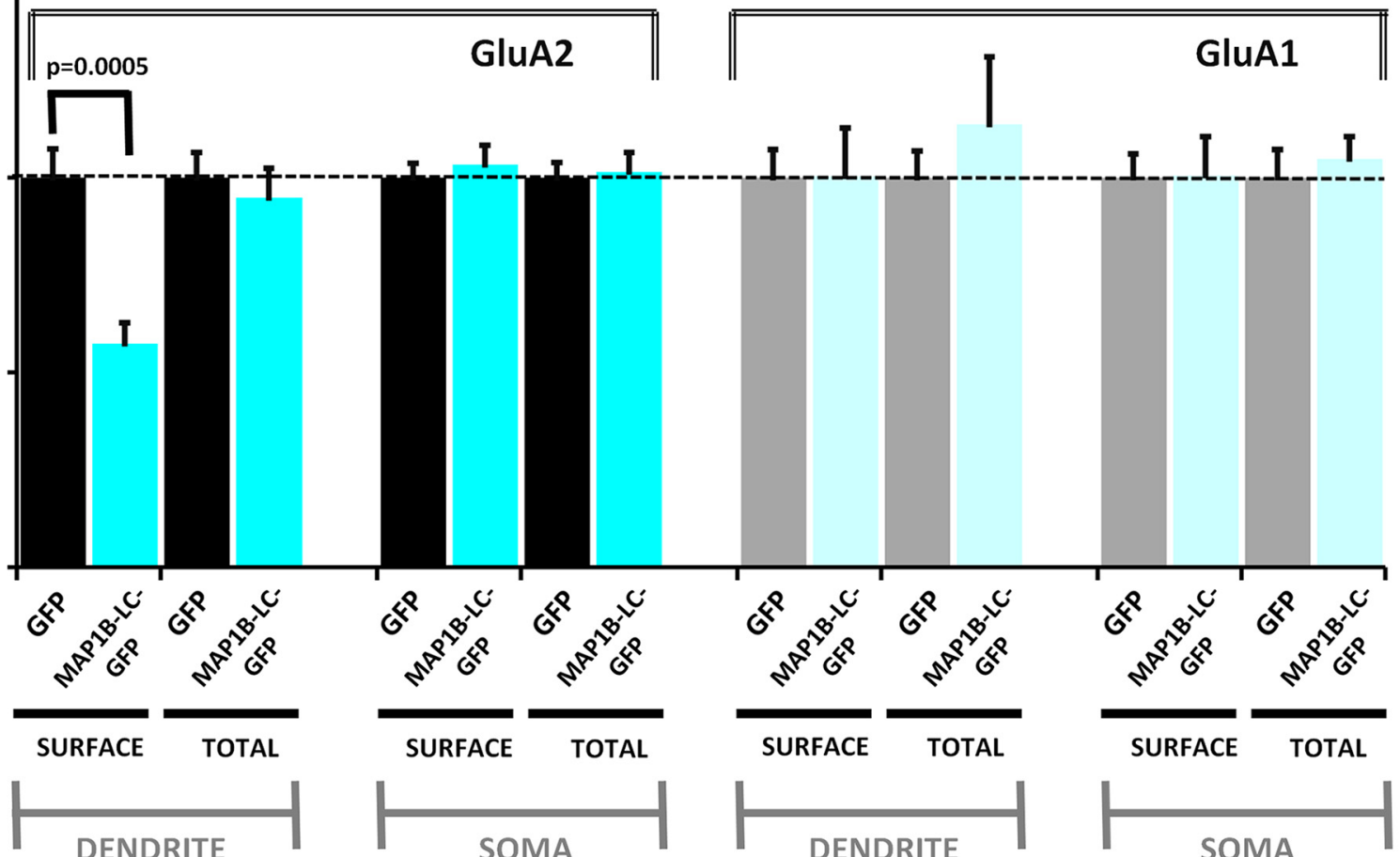

DENDRITE

SOMA

DENDRITE

SOMA

Figure 7. Differential effect of MAP1B-LC-GFP on GluA1 and GluA2 surface expression in hippocampal primary neurons.A, Representative images of hippocampal primary neurons expressing GFP (left three) or MAP1B-LC-GFP (right three) and stained against surface or total GluA2, as indicated. White rectangles indicate insets of representative dendritic branches shown in bottom panels. $B$, Same experiment as in $A$, but staining against surface and total GluA1. C, Quantification of fluorescence intensity corresponding to surface and total GluA2 and GluA1 in dendritic branches and soma of neurons expressing either GFP or MAP1B-LC-GFP, from experiments as those shown in $\boldsymbol{A}$ and $\boldsymbol{B} . n=20$ cells per condition. 
A

\section{Over-expression of GFP}

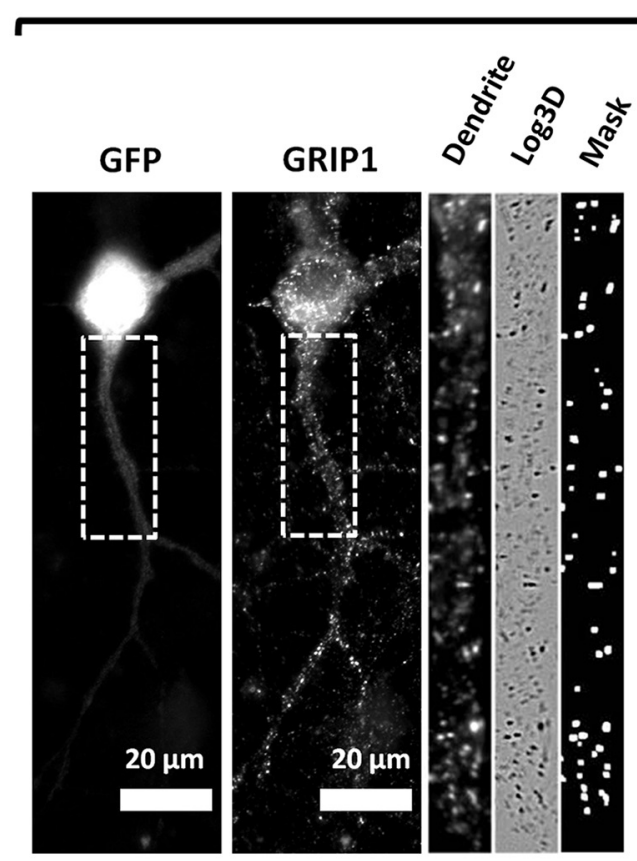

\section{Over-expression of MAP1B-LC-GFP}

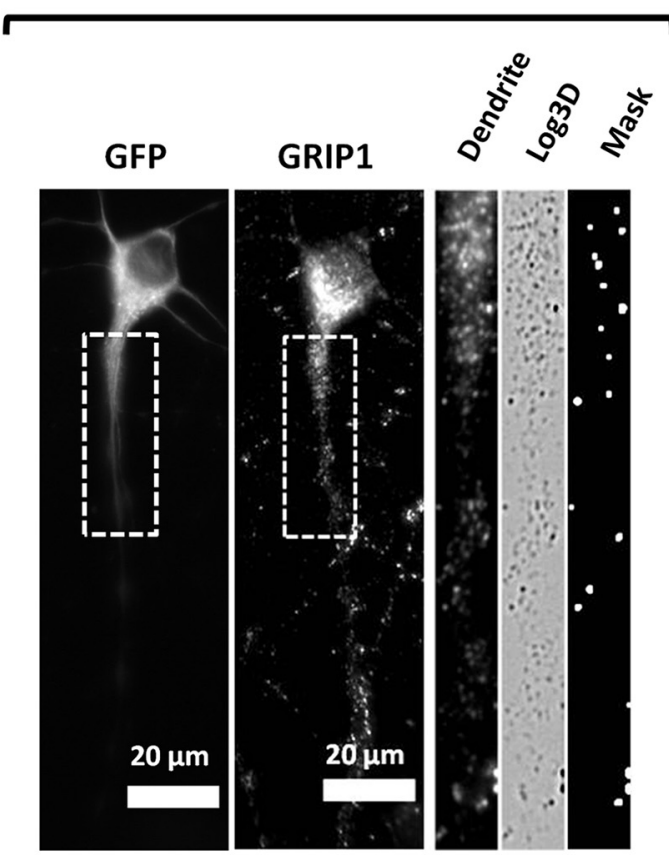

B

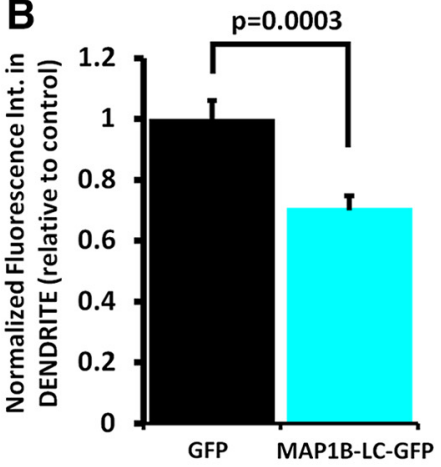

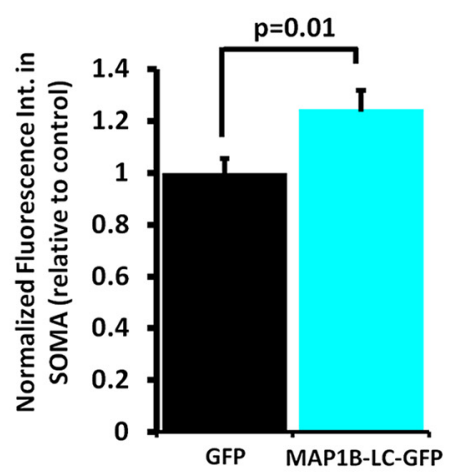

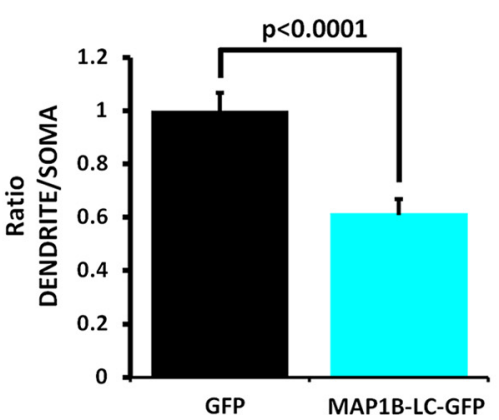

C
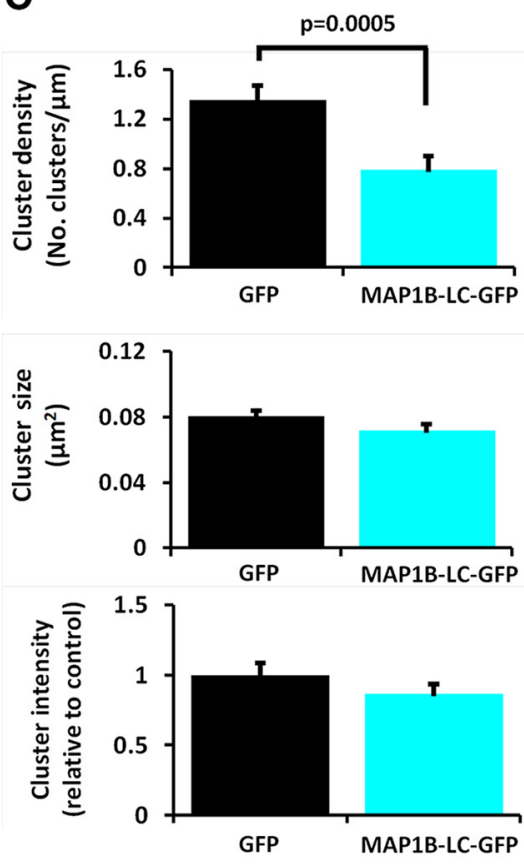

Figure 8. Expression of MAP1B-LC-GFP impairs GRIP1 dendritic targeting in hippocampal primary neurons. A, Representative examples of hippocampal primary neurons expressing GFP (left) or MAP1B-LC-GFP (right) and stained against GRIP1. Dashed rectangles correspond to dendrites shown on the right in higher magnification. The magnified dendritic segments were used as template for the Log3D-plugin (ImageJ) transformation ("Log3D”) and the generation of masks for GRIP1 cluster analysis. B, Quantification of fluorescence intensity (normalized to GFP control) for GRIP1 in dendrites (top left) and soma (top right) of cells expressing GFP ( $n=36$ cells) or MAP1B-LC-GFP ( $n=30$ cells). The ratio dendrite/soma for both types of neurons is shown below. $C$, Analysis of GRIP1 clusters along $50 \mu \mathrm{m}$ of dendrite (white dashed rectangles in $A$ ) from hippocampal primary neurons expressing GFP ( $n=26$ cells) or MAP1B-LC-GFP ( $n=23$ cells). Average cluster density, size, and fluorescence intensity (relative to GFP control) are presented.

shafts of CA1 neurons coexpressing either MAP1B-LC-mCherry or $\mathrm{mCherry}$ alone and the recovery of green fluorescence was followed for 20 min. As shown in Figure 6B, a fast and almost complete fluorescence recovery could be measured in dendrites of mCherry-expressing cells, indicating that, under these control conditions, receptors are fully mobile in the dendritic shaft. In contrast, the extent of fluorescence recovery was much smaller $(\sim 50 \%)$ in dendrites of cells overexpressing MAP1B-LC. This result indicates that MAP1B-LC overexpression reduces the fraction of mobile GluA2 AMPARs in dendrites. 
A
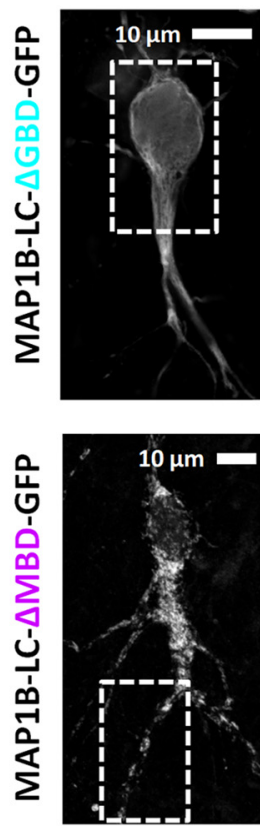

D

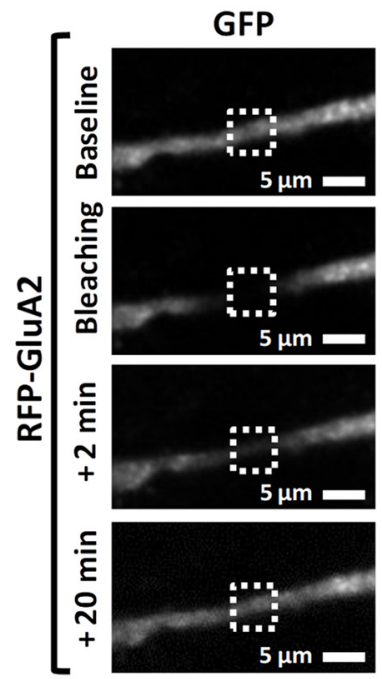

E

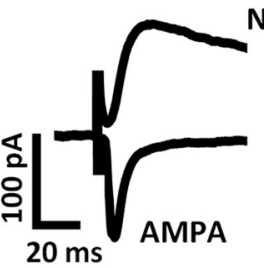

NMDA
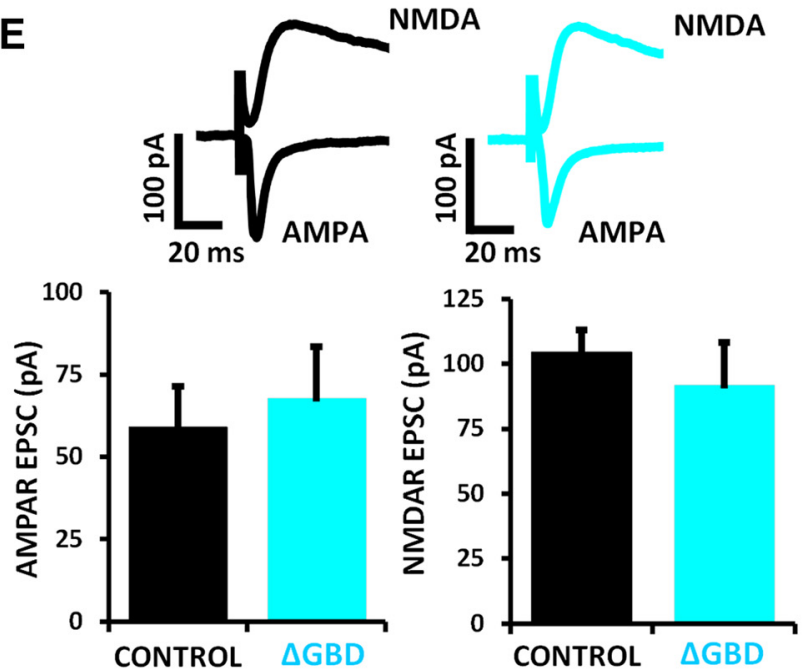

B

C 。
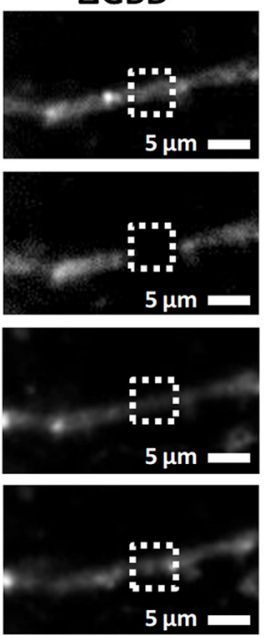

MAP1B-LC- $\triangle$ GBD-GFP MAP1B-LC- $\triangle M B D-G F P$

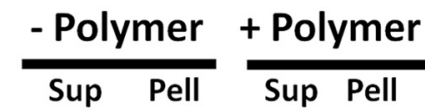

$\frac{\text { - Polymer }}{\text { Sup Pell }} \frac{+ \text { Polymer }}{\text { Sup Pell }}$

Actin co-sed assay

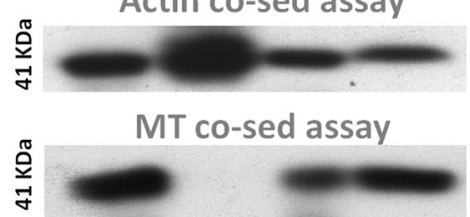

Actin co-sed assay

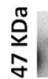
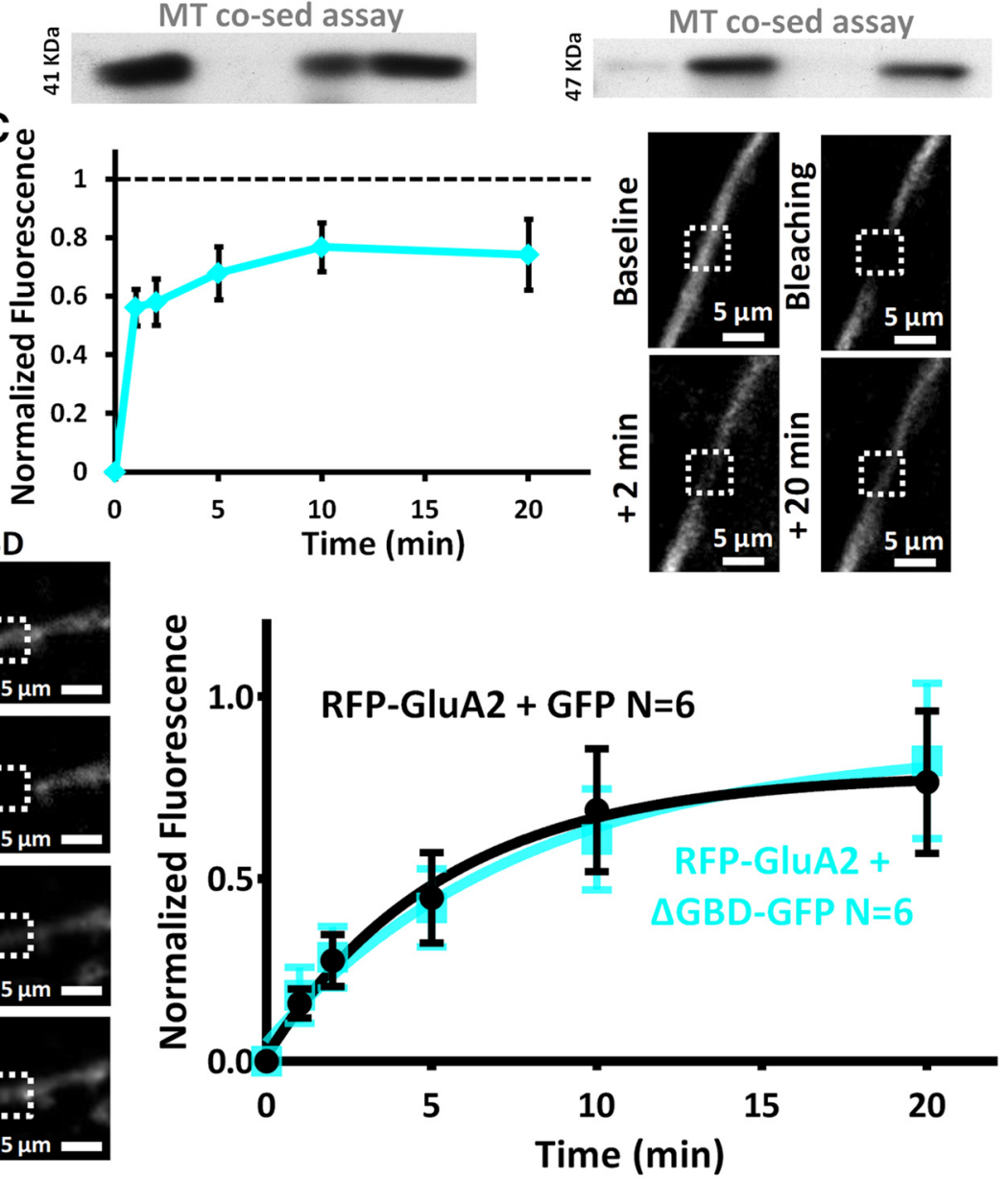

F
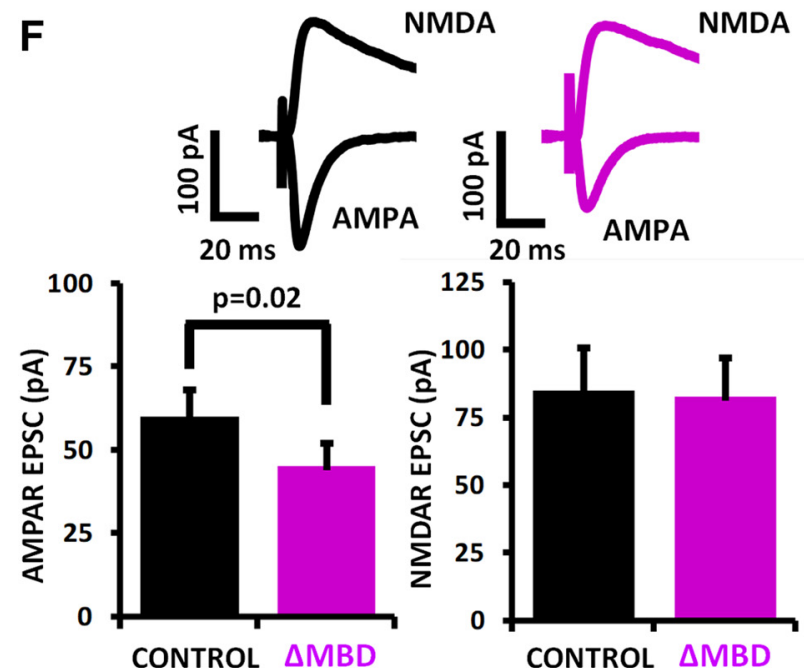

Figure 9. Differential contributions of microtubule- and GRIP1-binding domains of MAP1B-LC for AMPAR immobilization and synaptic depression. $A$, Confocal images of CA1 neurons showing the distribution of the MAP1B-LC mutant lacking the GRIP1/actin-binding domain (top, MAP1B-LC- $\triangle$ GBD-GFP) or the microtubule-binding domain (bottom, MAP1B-LC- $\triangle$ MBD-GFP). The rectangles in the left panels show the area amplified in the right panels. Arrows in the top panel point to filamentous appearance of MAP1B-LC- $\Delta$ GBD-GFP in the soma (Figure legend continues.) 
We then performed the FRAP experiments on dendrites coexpressing GFP-GluA1 with either MAP1B-LC-mCherry or mCherry alone. As shown in Figure 6C, the recovery profile was essentially complete (close to $100 \%$ ) and had an dentical time course for both conditions. This result again supports our hypothesis that MAP1B-LC restricts the trafficking of a specific population of AMPARs, particularly those controlled by the GluA2 subunit.

\section{Endogenous GluA2 AMPARs are trapped intracellularly by MAP1B-LC}

To evaluate whether the impaired vesicular trafficking and dendritic retention of AMPARs by MAP1B-LC has any impact on receptor surface delivery, we aimed to characterize the surface expression of endogenous AMPAR subunits in the dendrite and cell body of the neuron. Primary neurons were infected with the viral vector to express either MAP1B-LC-GFP or GFP as a control. Then, the surface or total population of GluA2-containing AMPARs was evaluated by consecutive immunostaining under nonpermeabilizing and permeabilizing conditions (see Materials and Methods). Quantifications were performed separately for the cell body and the dendritic compartment for each neuron. As shown in Figure 7, $A$ and $C$, surface expression of endogenous GluA2 was reduced significantly in the dendrites of neurons overexpressing MAP1B-LC-GFP compared with GFP-expressing neurons. Importantly, this reduction was not observed in the cell soma or in total protein expression (Fig. 7C). Again, this effect was specific for the GluA2 subunit. Therefore, the surface expression and total levels of the GluA1 subunit were unaffected in both dendrites and soma by the presence of overexpressed MAP1BLC-GFP (Fig. $7 B, C$ ). This result strengthens the interpretation that MAP1B-LC is able to modulate the surface delivery of endogenous GluA2-containing AMPARs, probably by restricting their movement within dendrites, without affecting the GluA1 population.

\section{MAP1B-LC impairs GRIP1 dendritic targeting}

All of the AMPAR trafficking effects that we have shown above for MAP1B-LC affected specifically the GluA2 AMPAR subunit. MAP1B-LC has been shown to interact with GRIP1 (Seog, 2004; Davidkova and Carroll, 2007). Conversely, GRIP1 has been proposed to act as the adaptor protein for GluA2-containing AMPARs in

\footnotetext{
$\leftarrow$

(Figure legend continued.) and apical dendrite. $\boldsymbol{B}$, Western blots of actin and microtubule co-sedimentation assays for MAP1B-LC- $\triangle$ GBD-GFP (left) and for MAP1B-LC- $\triangle$ MBD-GFP (right). C, Left, Quantification of FRAP experiments ( $n=7$ independent experiments) performed on the dendrites of hippocampal CA1 neurons expressing MAP1B-LC- $\triangle$ GBD-GFP. Right, Representative images of a dendrite of a neuron expressing MAP1B-LC- $\triangle$ GBD-GFP during a FRAP experiment. Images were acquired before photobleaching ("baseline"), immediately after photobleaching ("bleaching"), and at the indicated times during fluorescence recovery. Bleached regions are indicated with dashed squares. $\boldsymbol{D}$, Left, Representative images of RFPGluA2 at dendritic branches of neurons expressing either GFP or MAP1B- $\triangle$ GBD-LC-GFP during a FRAP experiment. Images were acquired before photobleaching ("baseline"), immediately after photobleaching ("bleaching"), and at the indicated times during fluorescence recovery. Bleached regions are indicated with dashed squares. Right, Quantification of RFP-GluA2 fluorescence at the dendrite normalized to the baseline value before photobleaching. Fluorescence intensity at the bleached area is normalized to a reference, "nonbleached" region of the dendrite to compensate for ongoing photobleaching during image acquisition. Time courses in both conditions were fitted to single exponentials. Nindicates the number of dendrites. $E$, Synaptic responses recorded from pairs of neighboring CA1 neurons expressing MAP1B-LC- $\triangle$ GBD-GFP (infected, INF) and control neurons (uninfected, UNINF) in the presence of picrotoxin at -60 $\mathrm{mV}$ for AMPARs ( $n=12$ pairs) and at $+40 \mathrm{mV}$ for NMDARs ( $n=11$ pairs). Representative traces are shown above. $\boldsymbol{F}$, Same experiment as in $\boldsymbol{E}$, but expressing MAP1B-LC- $\triangle$ MBD-GFP (AMPAR responses, $n=28$ pairs; NMDAR responses, $n=27$ pairs).
}

kinesin-dependent transport along microtubules (Setou et al., 2002). Therefore, we tested whether MAP1B-LC regulates GRIP1 trafficking. To this end, we measured endogenous GRIP1 distribution in hippocampal primary neurons overexpressing MAP1BLC-GFP or GFP as a control (Fig. 8A). Mean fluorescence intensity from GRIP1 immunostaining was measured at the cell soma and at dendritic regions $50 \mu \mathrm{m}$ in length adjacent to the cell soma. In neurons overexpressing MAP1B-LC-GFP, the fluorescence intensity corresponding to GRIP1 was increased in the cell body and decreased in dendrites, yielding a reduced dendrite/ soma ratio compared with GFP-expressing neurons (Fig. 8B). In addition, we measured total number, size, and fluorescence intensity of GRIP1 clusters in the $50 \mu \mathrm{m}$ dendritic region. As shown in Figure $8 C$, the number of GRIP1 clusters was reduced significantly in neurons overexpressing MAP1B-LC-GFP compared with those overexpressing GFP without altering the size of these clusters or their GRIP1 content (evaluated from the fluorescence intensity of each cluster). Together, these data indicate that MAP1B-LC impairs the delivery of GRIP1 from the cell body toward the dendrites. Because GRIP1 couples GluA2 AMPARs with motor proteins for their microtubule-dependent dendritic transport (Setou et al., 2002; Shin et al., 2003), these results supports the scenario of an increased immobile pool of AMPARs in the dendritic shaft by MAP1B-LC and, therefore, a reduced availability of AMPARs for spine and synaptic insertion.

\section{GRIP1-binding domain of MAP1B-LC is required to decrease basal synaptic transmission}

The LC of MAP1B is composed of a domain that binds GRIP1 (which also binds actin filaments) and a domain that mediates binding to microtubules (Zauner et al., 1992; Tögel et al., 1998; Seog, 2004; Davidkova and Carroll, 2007). To evaluate the role of MAP1B-LC protein-protein interactions in its effects on synaptic transmission, we generated two deletion mutants of MAP1B-LC: a mutant lacking the GRIP1/actin-binding domain (MAP1B-LC$\triangle \mathrm{GBD})$ and a mutant lacking the microtubule-binding domain (MAP1B-LC- $\triangle \mathrm{MBD}$ ). As shown in Figure $9 A$, both constructs expressed well and distributed throughout cell body and dendrites in CA1 neurons.

To test the protein integrity and functionality of both mutants, we designed in vitro co-sedimentation assays aimed at testing their interaction with microtubules or filamentous actin, respectively. As shown in Figure 9B, left, MAP1B-LC- $\Delta$ GBD sedimentation did not increase with the addition of filamentous actin, consistent with the role of the GBD in actin binding. In contrast, the addition of microtubules triggered MAP1B-LC$\triangle \mathrm{GBD}$ sedimentation, demonstrating its integrity and ability to interact with microtubules. The opposite situation was observed with the mutant lacking the microtubule-binding domain (Fig. $9 B$, right): MAP1B-LC- $\triangle \mathrm{MBD}-\mathrm{GFP}$ sedimented in the presence of exogenously added filamentous actin, but was insensitive to the presence of taxol-stabilized microtubules.

After verifying the structural integrity of these mutants, we tested their effect on AMPAR function. Using FRAP experiments, we first observed that a significant fraction of MAP1B-LC- $\Delta \mathrm{GBD}$ remains immobile in dendrites (Fig. 9 C), probably because of its microtubule-binding domain. Nevertheless, the immobile fraction of this mutant was clearly smaller than that of the wild-type protein (cf. FRAP experiment in Fig. 2A), suggesting that the MBD is not sufficient for full MAP1B-LC anchoring. Importantly, this mutant was no longer able to interfere with GluA2 dendritic mobility, as assayed by FRAP experiments on RFPGluA2 coexpressed with MAP1B-LC- $\Delta$ GBD-GFP or with GFP as 
a control (Fig. 9D). Accordingly, we did not observe any significant difference between AMPAR- or NMDAR-dependent transmission in neurons overexpressing MAP1B-LC- $\Delta$ GBD compared with control neurons (Fig. 9E). In contrast, overexpression of MAP1B-LC- $\triangle \mathrm{MBD}$ did produce a significant depression of AMPAR-mediated responses compared with control neurons (Fig. 9F). This result suggests that the GRIP1-binding domain present in this mutant is sufficient to interfere with the synaptic function of GRIP1-AMPAR complexes even in the absence of microtubule binding.

\section{Discussion}

In this work, we show that MAP1B-LC concentrates at the somatodendritic compartment of the neuron separately from its HC counterpart. Within this compartment, MAP1B-LC forms stable complexes with dendritic microtubules. This MAP1B-LC lattice acts as an intracellular trap that restricts vesicular trafficking and limits AMPAR availability for synaptic insertion. This trapping mechanism is mediated by GRIP1-GluA2 interactions. In this manner, it targets specifically AMPARs that traffic continuously into synapses and therefore has a direct impact on basal synaptic transmission. In contrast, it does not interfere with the regulated trafficking and synaptic delivery of AMPARs during LTP, which is dominated by GluA1 interactions (Hayashi et al., 2000; Passafaro et al., 2001; Shi et al., 2001; but see also Granger et al., 2013). It has also been shown recently that constitutive and activitydependent endocytosis engage different molecular machinery (Glebov et al., 2015). Nevertheless, it is also important to note that multiple mechanisms for constitutive recycling of AMPARs may coexist, potentially involving different subunits. For example, GluA1 subunits have been shown to traffic in and out of synapses independently from synaptic plasticity in a recycling endosomal pool controlled by the small GTPases TC20 and Arf6 (Zheng et al., 2015). Because we did not observe any effect on GluA1 subunits upon overexpression of MAP1B-LC, this appears to be a different recycling pool from the one that we are describing here.

The novel role we propose here for MAP1B-LC is based on its ability to interact with stable microtubules and GRIP1, which provides an immobile scaffold linking AMPARs to the microtubule cytoskeleton. Importantly, this molecular complex would be functionally very different from the one mediating microtubuledependent transport of AMPARs via GRIP1-kinesin interactions (Setou et al., 2002; Shin et al., 2003). By associating with MAP1B-LC instead of with kinesin motors, GRIP1 would become immobilized onto microtubules, therefore trapping the associated AMPARs with it and restricting their access to the synaptic mem-
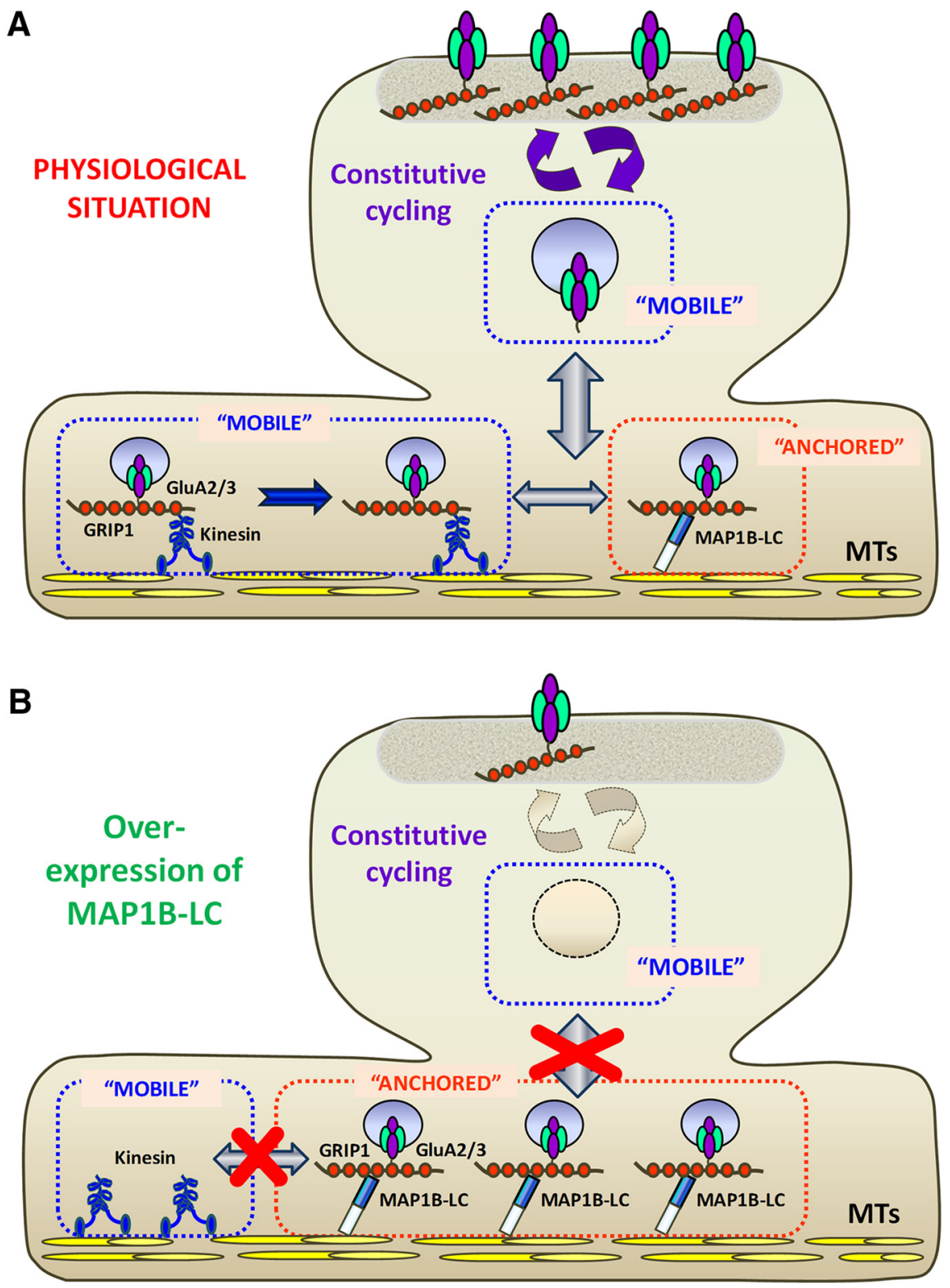

Figure 10. Model for MAP1B-LC function in AMPAR trafficking. $\boldsymbol{A}$, Under physiological conditions, GluA2/3-GRIP1 complexes may interact with kinesin motors that power their forward transport along dendrites or with MAP1B-LC, which mediates the AMPARs that enters dendritic spines and participates in the constitutive cycling at synapses for the maintenance of basal transmission. $\boldsymbol{B}$, After an increase in MAP1B-LC levels, the equilibrium between the mobile and anchored populations of GluA2/3-GRIP1 synapses. AMPAR stabilization at synapses might be also impaired as a result of GRIP1 depletion from the postsynaptic density. Both mechanisms probably contribute to the observed reduction of basal transmission.

brane. Nevertheless, AMPARs appear to have GRIP1-independent mechanisms to reach the dendritic compartment because MAP1B-LC overexpression interfered with the export from soma to dendrites for GRIP1, but not for AMPARs. Conversely, the reduced distribution of GRIP1 into dendrites is also expected to interfere with its function as a synaptic anchoring molecule and this mechanism may also contribute to a reduced accumulation of AMPARs at synapses (see model in Fig. 10).

MAP1B-LC has been shown previously to interact with other membrane proteins such as the voltage-gated calcium channel $\mathrm{Ca}_{\mathrm{V}} 2.2$ (Gandini et al., 2014a; Gandini et al., 2014b) and sodium channel $\mathrm{Na}_{\mathrm{v}} 1.6$ (O'Brien et al., 2012), as well as the serotonin receptor 5-HT3 (Sun et al., 2008). In all of these cases, the inter- 
action of MAP1B-LC with the membrane protein is direct and the functional consequences range from internalization and proteasome-mediated degradation $\left(\mathrm{Ca}_{\mathrm{V}} 2.2\right)$ to increased surface expression $\left(\mathrm{Na}_{\mathrm{v}} 1.6\right)$ to modulation of channel gating (5-HT3). In the case that we describe here for AMPARs, the molecular link between MAP1B-LC and GRIP1 explains the specific receptor population that is affected. We have observed that MAP1B-LC does not affect the dendritic mobility, surface expression, or spine entry of GluA1 subunits. The transport of GluA1-containing AMPARs from the cell body toward spines is still poorly understood. The PDZ-domain-containing protein SAP97 interacts with the $\mathrm{C}$ terminus of GluA1 and has been proposed to play a role in this process (Leonard et al., 1998; Sans et al., 2001). In this scenario, AMPARs controlled by GluA1 or GluA2 interactions would be transported in different vesicles early on in the biosynthetic pathway. This is consistent with the differential retention at the endoplasmic reticulum described for GluA1 and GluA2 subunits (Greger et al., 2002; Greger and Esteban, 2007) and with the different subcellular profiles obtained for these subunits in biochemical fractionations (Lee et al., 2001). This is also consistent with the different membrane dynamics observed for recombinant GluA1 and GluA2 receptors in hippocampal primary neurons (Perestenko and Henley, 2003).

What is the physiological significance of this microtubuletrapping mechanism for GRIP1-GluA2 mediated by MAP1B-LC? GRIP1 has been proposed to play different (and sometimes conflicting) roles in AMPAR trafficking, from the recycling of receptors toward the synaptic membrane to their intracellular retention after endocytosis (Dong et al., 1997; Srivastava et al., 1998; Dong et al., 1999; Wyszynski et al., 1999; Daw et al., 2000; Osten et al., 2000; Wyszynski et al., 2002; Alberi et al., 2005; Lu and Ziff, 2005; Steiner et al., 2005; Mao et al., 2010). These opposite effects may fit well with the alternative complexes that we are proposing here for GRIP1-GluA2: engagement with kinesin motors would lead to forward trafficking along microtubules, whereas coupling to MAP1B-LC would produce immobilization and trapping onto stable microtubules (Fig. 10). A braking action of MAP1B-LC on microtubule-dependent transport is also supported by the observation that mitochondrial retrograde transport is accelerated in the axons of MAP1B knockout neurons (Jiménez-Mateos et al., 2006), similar to our results on dendritic transport of TfR with MAP1B knockdown neurons.

It is also important to point out that the levels of MAP1B-LC expression are regulated under physiological conditions during synaptic plasticity (Davidkova and Carroll, 2007; Chen and Shen, 2013) and under some pathological conditions such as giant axonal neuropathy (Johnson-Kerner et al., 2014). This pathology is caused by mutations in gigaxonin (Bomont et al., 2000), an ubiquitin-scaffolding protein that interacts specifically with MAP1B-LC (vs MAP1B-HC) and directs its proteasomal degradation (Ding et al., 2002; Allen et al., 2005). Deficiencies in gigaxonin function lead to the accumulation of MAP1B-LC (Allen et al., 2005) and impairment of axonal transport (Ding et al., 2006).

These studies strengthen the notion of independent functions of the LC of MAP1B and suggest a new mechanism for the control of synaptic function based on trapping AMPARs at immobile microtubular scaffolds.

\section{References}

Alberi S, Boda B, Steiner P, Nikonenko I, Hirling H, Muller D (2005) The endosomal protein NEEP21 regulates AMPA receptor-mediated synaptic transmission and plasticity in the hippocampus. Mol Cell Neurosci 29: 313-319. CrossRef Medline
Allen E, Ding J, Wang W, Pramanik S, Chou J, Yau V, Yang Y (2005) Gigaxonin-controlled degradation of MAP1B light chain is critical to neuronal survival. Nature 438:224-228. CrossRef Medline

Benoist M, Palenzuela R, Rozas C, Rojas P, Tortosa E, Morales B, GonzálezBillault C, Ávila J, Esteban JA (2013) MAP1B-dependent Rac activation is required for AMPA receptor endocytosis during long-term depression. EMBO J 32:2287-2299. CrossRef Medline

Bliss TV, Collingridge GL (1993) A synaptic model of memory: long-term potentiation in the hippocampus. Nature 361:31-39. CrossRef Medline

Bodaleo FJ, Montenegro-Venegas C, Henríquez DR, Court FA, GonzalezBillault C (2016) Microtubule-associated protein 1B (MAP1B)-deficient neurons show structural presynaptic deficiencies in vitro and altered presynaptic physiology. Sci Rep 6:30069. CrossRef Medline

Bomont P, Cavalier L, Blondeau F, Ben Hamida C, Belal S, Tazir M, Demir E, Topaloglu H, Korinthenberg R, Tüysüz B, Landrieu P, Hentati F, Koenig $M$ (2000) The gene encoding gigaxonin, a new member of the cytoskeletal BTB/kelch repeat family, is mutated in giant axonal neuropathy. Nat Genet 26:370-374. CrossRef Medline

Campbell JN, Slep KC (2011) alphabeta-Tubulin and microtubule-binding assays. Methods Mol Biol 777:87-97. CrossRef Medline

Chen YL, Shen CK (2013) Modulation of mGluR-dependent MAP1B translation and AMPA receptor endocytosis by MicroRNA miR-146a-5p. J Neurosci 33:9013-9020. CrossRef Medline

Davidkova G, Carroll RC (2007) Characterization of the role of microtubuleassociated protein $1 \mathrm{~B}$ in metabotropic glutamate receptor-mediated endocytosis of AMPA receptors in hippocampus. J Neurosci 27:13273-13278. CrossRef Medline

Daw MI, Chittajallu R, Bortolotto ZA, Dev KK, Duprat F, Henley JM, Collingridge GL, Isaac JT (2000) PDZ proteins interacting with C-terminal GluR2/3 are involved in a PKC-dependent regulation of AMPA receptors at hippocampal synapses. Neuron 28:873-886. CrossRef Medline

Derkach VA, Oh MC, Guire ES, Soderling TR (2007) Regulatory mechanisms of AMPA receptors in synaptic plasticity. Nat Rev Neurosci 8:101113. CrossRef Medline

Ding J, Liu JJ, Kowal AS, Nardine T, Bhattacharya P, Lee A, Yang Y (2002) Microtubule-associated protein 1B: a neuronal binding partner for gigaxonin. J Cell Biol 158:427-433. CrossRef Medline

Ding J, Allen E, Wang W, Valle A, Wu C, Nardine T, Cui B, Yi J, Taylor A, Jeon NL, Chu S, So Y, Vogel H, Tolwani R, Mobley W, Yang Y (2006) Gene targeting of GAN in mouse causes a toxic accumulation of microtubuleassociated protein 8 and impaired retrograde axonal transport. Hum Mol Genet 15:1451-1463. CrossRef Medline

Dong H, O’Brien RJ, Fung ET, Lanahan AA, Worley PF, Huganir RL (1997) GRIP: a synaptic PDZ domain-containing protein that interacts with AMPA receptors. Nature 386:279-284. CrossRef Medline

Dong H, Zhang P, Song I, Petralia RS, Liao D, Huganir RL (1999) Characterization of the glutamate receptor-interacting proteins GRIP1 and GRIP2. J Neurosci 19:6930-6941. Medline

Elias GM, Nicoll RA (2007) Synaptic trafficking of glutamate receptors by MAGUK scaffolding proteins. Trends Cell Biol 17:343-352. CrossRef Medline

Gandini MA, Sandoval A, Zamponi GW, Felix R (2014a) The MAP1B-LC1/ UBE2L3 complex catalyzes degradation of cell surface CaV2.2 channels. Channels (Austin) 8:452-457. CrossRef Medline

Gandini MA, Henríquez DR, Grimaldo L, Sandoval A, Altier C, Zamponi GW, Felix R, González-Billault C (2014b) CaV2.2 channel cell surface expression is regulated by the light chain 1 (LC1) of the microtubuleassociated protein B (MAP1B) via UBE2L3-mediated ubiquitination and degradation. Pflugers Arch 466:2113-2126. CrossRef Medline

Gerges NZ, Brown TC, Correia SS, Esteban JA (2005) Analysis of Rab protein function in neurotransmitter receptor trafficking at hippocampal synapses. Methods Enzymol 403:153-166. CrossRef Medline

Glebov OO, Tigaret CM, Mellor JR, Henley JM (2015) Clathrin-independent trafficking of AMPA receptors. J Neurosci 35:4830-4836. CrossRef Medline

Gonzalez-Billault C, Avila J, Cáceres A (2001) Evidence for the role of MAP1B in axon formation. Mol Biol Cell 12:2087-2098. CrossRef Medline

Gonzalez-Billault C, Owen R, Gordon-Weeks PR, Avila J (2002) Microtubule-associated protein $1 \mathrm{~B}$ is involved in the initial stages of axonogenesis in peripheral nervous system cultured neurons. Brain Res 943:56-67. CrossRef Medline

Granger AJ, Shi Y, Lu W, Cerpas M, Nicoll RA (2013) LTP requires a reserve 
pool of glutamate receptors independent of subunit type. Nature 493: 495-500. CrossRef Medline

Greger IH, Esteban JA (2007) AMPA receptor biogenesis and trafficking. Curr Opin Neurobiol 17:289-297. CrossRef Medline

Greger IH, Khatri L, Ziff EB (2002) RNA editing at arg607 controls AMPA receptor exit from the endoplasmic reticulum. Neuron 34:759-772. CrossRef Medline

Gurskaya NG, Verkhusha VV, Shcheglov AS, Staroverov DB, Chepurnykh TV, Fradkov AF, Lukyanov S, Lukyanov KA (2006) Engineering of a monomeric green-to-red photoactivatable fluorescent protein induced by blue light. Nat Biotechnol 24:461-465. CrossRef Medline

Halpain S, Dehmelt L (2006) The MAP1 family of microtubule-associated proteins. Genome Biol 7:224. CrossRef Medline

Hammarback JA, Obar RA, Hughes SM, Vallee RB (1991) MAP1B is encoded as a polyprotein that is processed to form a complex $\mathrm{N}$-terminal microtubule-binding domain. Neuron 7:129-139. CrossRef Medline

Hayashi Y, Shi SH, Esteban JA, Piccini A, Poncer JC, Malinow R (2000) Driving AMPA receptors into synapses by LTP and CaMKII: requirement for GluR1 and PDZ domain interaction. Science 287:2262-2267. CrossRef Medline

Heisler FF, Lee HK, Gromova KV, Pechmann Y, Schurek B, Ruschkies L, Schroeder M, Schweizer M, Kneussel M (2014) GRIP1 interlinks N-cadherin and AMPA receptors at vesicles to promote combined cargo transport into dendrites. Proc Natl Acad Sci U S A 111:5030-5035. CrossRef Medline

Hernandez R, Brown DT (2010) Growth and maintenance of baby hamster kidney (BHK) cells. Curr Protoc Microbiol Chapter 4:Appendix 4H. CrossRef Medline

Herring BE, Nicoll RA (2016) Long-term potentiation: from CaMKII to AMPA receptor trafficking. Annu Rev Physiol 78:351-365. CrossRef Medline

Hollmann M, Heinemann S (1994) Cloned glutamate receptors. Annu Rev Neurosci 17:31-108. CrossRef Medline

Hoogenraad CC, Milstein AD, Ethell IM, Henkemeyer M, Sheng M (2005) GRIP1 controls dendrite morphogenesis by regulating EphB receptor trafficking. Nat Neurosci 8:906-915. CrossRef Medline

Hu X, Viesselmann C, Nam S, Merriam E, Dent EW (2008) Activitydependent dynamic microtubule invasion of dendritic spines. J Neurosci 28:13094-13105. CrossRef Medline

Hu X, Ballo L, Pietila L, Viesselmann C, Ballweg J, Lumbard D, Stevenson M, Merriam E, Dent EW (2011) BDNF-induced increase of PSD-95 in dendritic spines requires dynamic microtubule invasions. J Neurosci 31: 15597-15603. CrossRef Medline

Huber KM, Roder JC, Bear MF (2001) Chemical induction of mGluR5- and protein synthesis-dependent long-term depression in hippocampal area CA1. J Neurophysiol 86:321-325. Medline

Jaworski J, Kapitein LC, Gouveia SM, Dortland BR, Wulf PS, Grigoriev I, Camera P, Spangler SA, Di Stefano P, Demmers J, Krugers H, Defilippi P, Akhmanova A, Hoogenraad CC (2009) Dynamic microtubules regulate dendritic spine morphology and synaptic plasticity. Neuron 61:85-100. CrossRef Medline

Jia Z, Agopyan N, Miu P, Xiong Z, Henderson J, Gerlai R, Taverna FA, Velumian A, MacDonald J, Carlen P, Abramow-Newerly W, Roder J (1996) Enhanced LTP in mice deficient in the AMPA receptor GluR2. Neuron 17:945-956. CrossRef Medline

Jiménez-Mateos EM, González-Billault C, Dawson HN, Vitek MP, Avila J (2006) Role of MAP1B in axonal retrograde transport of mitochondria. Biochem J 397:53-59. CrossRef Medline

Johnson-Kerner BL, Roth L, Greene JP, Wichterle H, Sproule DM (2014) Giant axonal neuropathy: An updated perspective on its pathology and pathogenesis. Muscle Nerve 50:467-476. CrossRef Medline

Jolly AL, Kim H, Srinivasan D, Lakonishok M, Larson AG, Gelfand VI (2010) Kinesin-1 heavy chain mediates microtubule sliding to drive changes in cell shape. Proc Natl Acad Sci USA 107:12151-12156. CrossRef Medline

Kennedy MJ, Ehlers MD (2006) Organelles and trafficking machinery for postsynaptic plasticity. Annu Rev Neurosci 29:325-362. CrossRef Medline

Kessels HW, Malinow R (2009) Synaptic AMPA receptor plasticity and behavior. Neuron 61:340-350. CrossRef Medline

Kreis TE (1987) Microtubules containing detyrosinated tubulin are less dynamic. EMBO J 6:2597-2606. Medline

Lee SH, Valtschanoff JG, Kharazia VN., Weinberg R, Sheng M (2001) Biochemical and morphological characterization of an intracellular mem- brane compartment containing AMPA receptors. Neuropharmacology 41:680-692. CrossRef Medline

Leonard AS, Davare MA, Horne MC, Garner CC, Hell JW (1998) SAP97 is associated with the alpha-amino-3-hydroxy-5-methylisoxazole-4-propionic acid receptor GluR1 subunit. J Biol Chem 273:19518-19524. CrossRef Medline

Lo DC, McAllister AK, Katz LC (1994) Neuronal transfection in brain slices using particle-mediated gene transfer. Neuron 13:1263-1268. CrossRef Medline

Lu W, Ziff EB (2005) PICK1 interacts with ABP/GRIP to regulate AMPA receptor trafficking. Neuron 47:407-421. CrossRef Medline

Lüscher C, Malenka RC (2012) NMDA receptor-dependent long-term potentiation and long-term depression (LTP/LTD). Cold Spring Harb Perspect Biol 4: pii: a005710. CrossRef Medline

Lüscher C, Xia H, Beattie EC, Carroll RC, von Zastrow M, Malenka RC, Nicoll RA (1999) Role of AMPA receptor cycling in synaptic transmission and plasticity. Neuron 24:649-658. CrossRef Medline

Malinow R, Hayashi Y, Maletic-Savatic M, Zaman SH, Poncer JC, Shi SH, Esteban JA, Osten P, Seidenman K (2010) Introduction of green fluorescent protein (GFP) into hippocampal neurons through viral infection. Cold Spring Harb Protoc 4:pdb.prot5406. CrossRef Medline

Mao L, Takamiya K, Thomas G, Lin DT, Huganir RL (2010) GRIP1 and 2 regulate activity-dependent AMPA receptor recycling via exocyst complex interactions. Proc Natl Acad Sci U S A 107:19038-19043. CrossRef Medline

Mei X, Sweatt AJ, Hammarback JA (2000) Regulation of microtubuleassociated protein 1B (MAP1B) subunit composition. J Neurosci Res 62:56-64. Medline

Merriam EB, Lumbard DC, Viesselmann C, Ballweg J, Stevenson M, Pietila L, Hu X, Dent EW (2011) Dynamic microtubules promote synaptic NMDA receptor-dependent spine enlargement. PLoS One 6:e27688. CrossRef Medline

Nakamura Y, Wood CL, Patton AP, Jaafari N, Henley JM, Mellor JR, Hanley JG (2011) PICK1 inhibition of the Arp2/3 complex controls dendritic spine size and synaptic plasticity. EMBO J 30:719-730. CrossRef Medline

Nishimune A, Isaac JT, Molnar E, Noel J, Nash SR, Tagaya M, Collingridge GL, Nakanishi S, Henley JM (1998) NSF binding to GluR2 regulates synaptic transmission. Neuron 21:87-97. CrossRef Medline

Noel J, Ralph GS, Pickard L, Williams J, Molnar E, Uney JB, Collingridge GL, Henley JM (1999) Surface expression of AMPA receptors in hippocampal neurons is regulated by an NSF-dependent mechanism. Neuron 23: 365-376. CrossRef Medline

Noiges R, Eichinger R, Kutschera W, Fischer I, Nemeth Z, Wiche G, Propst F (2002) Microtubule-associated protein 1A (MAP1A) and MAP1B: light chains determine distinct functional properties. J Neurosci 22:21062114. Medline

O'Brien JE, Sharkey LM, Vallianatos CN, Han C, Blossom JC, Yu T, Waxman SG, Dib-Hajj SD, Meisler MH (2012) Interaction of voltage-gated sodium channel Nav1.6 (SCN8A) with microtubule-associated protein Map1b. J Biol Chem 287:18459-18466. CrossRef Medline

Osten P, Khatri L, Perez JL, Köhr G, Giese G, Daly C, Schulz TW, Wensky A, Lee LM, Ziff EB (2000) Mutagenesis reveals a role for ABP/GRIP binding to GluR2 in synaptic surface accumulation of the AMPA receptor. Neuron 27:313-325. CrossRef Medline

Passafaro M, Piëch V, Sheng M (2001) Subunit-specific temporal and spatial patterns of AMPA receptor exocytosis in hippocampal neurons. Nat Neurosci 4:917-926. CrossRef Medline

Pedrotti B, Islam K (1995) Microtubule associated protein 1B (MAP1B) promotes efficient tubulin polymerisation in vitro. FEBS Lett 371:29-31. CrossRef Medline

Perestenko PV, Henley JM (2003) Characterization of the intracellular transport of GluR1 and GluR2 alpha-amino-3-hydroxy-5-methyl-4isoxazole propionic acid receptor subunits in hippocampal neurons. J Biol Chem 278:43525-43532. CrossRef Medline

Piperno G, LeDizet M, Chang XJ (1987) Microtubules containing acetylated alpha-tubulin in mammalian cells in culture. J Cell Biol 104:289-302. CrossRef Medline

Rocca DL, Martin S, Jenkins EL, Hanley JG (2008) Inhibition of Arp2/3mediated actin polymerization by PICK1 regulates neuronal morphology and AMPA receptor endocytosis. Nat Cell Biol 10:259-271. CrossRef Medline

Rocca DL, Amici M, Antoniou A, Blanco Suarez E, Halemani N, Murk K, 
McGarvey J, Jaafari N, Mellor JR, Collingridge GL, Hanley JG (2013) The small GTPase Arf1 modulates Arp2/3-mediated actin polymerization via PICK1 to regulate synaptic plasticity. Neuron 79:293-307. CrossRef Medline

Sage D, Neumann FR, Hediger F, Gasser SM, Unser M (2005) Automatic tracking of individual fluorescence particles: application to the study of chromosome dynamics. IEEE Trans Image Process 14:1372-1383. CrossRef Medline

Sans N, Racca C, Petralia RS, Wang YX, McCallum J, Wenthold RJ (2001) Synapse-associated protein 97 selectively associates with a subset of AMPA receptors early in their biosynthetic pathway. J Neurosci 21:75067516. Medline

Schulze E, Asai DJ, Bulinski JC, Kirschner M (1987) Posttranslational modification and microtubule stability. J Cell Biol 105:2167-2177. CrossRef Medline

Seog DH (2004) Glutamate receptor-interacting protein 1 protein binds to the microtubule-associated protein. Biosci Biotechnol Biochem 68:18081810. CrossRef Medline

Setou M, Seog DH, Tanaka Y, Kanai Y, Takei Y, Kawagishi M, Hirokawa N (2002) Glutamate-receptor-interacting protein GRIP1 directly steers kinesin to dendrites. Nature 417:83-87. CrossRef Medline

Shepherd JD, Huganir RL (2007) The cell biology of synaptic plasticity: AMPA receptor trafficking. Annu Rev Cell Dev Biol 23:613-643. CrossRef Medline

Shi S, Hayashi Y, Esteban JA, Malinow R (2001) Subunit-specific rules governing AMPA receptor trafficking to synapses in hippocampal pyramidal neurons. Cell 105:331-343. CrossRef Medline

Shin H, Wyszynski M, Huh KH, Valtschanoff JG, Lee JR, Ko J, Streuli M, Weinberg RJ, Sheng M, Kim E (2003) Association of the kinesin motor KIF1A with the multimodular protein liprin-alpha. J Biol Chem 278: 11393-11401. CrossRef Medline

Song I, Kamboj S, Xia J, Dong H, Liao D, Huganir RL (1998) Interaction of the N-ethylmaleimide-sensitive factor with AMPA receptors. Neuron 21: 393-400. CrossRef Medline

Srivastava S, Osten P, Vilim FS, Khatri L, Inman G, States B, Daly C, DeSouza S, Abagyan R, Valtschanoff JG, Weinberg RJ, Ziff EB (1998) Novel anchorage of GluR2/3 to the postsynaptic density by the AMPA receptorbinding protein ABP. Neuron 21:581-591. CrossRef Medline

Steiner P, Alberi S, Kulangara K, Yersin A, Sarria JC, Regulier E, Kasas S, Dietler G, Muller D, Catsicas S, Hirling H (2005) Interactions between NEEP21, GRIP1 and GluR2 regulate sorting and recycling of the glutamate receptor subunit GluR2. EMBO J 24:2873-2884. CrossRef Medline

Sun H, Hu XQ, Emerit MB, Schoenebeck JC, Kimmel CE, Peoples RW, Miko A, Zhang L (2008) Modulation of 5-HT3 receptor desensitization by the light chain of microtubule-associated protein 1B expressed in HEK 293 cells. J Physiol 586:751-762. CrossRef Medline
Tögel M, Wiche G, Propst F (1998) Novel features of the light chain of microtubule-associated protein MAP1B: microtubule stabilization, self interaction, actin filament binding, and regulation by the heavy chain. J Cell Biol 143:695-707. CrossRef Medline

Tortosa E, Montenegro-Venegas C, Benoist M, Härtel S, González-Billault C, Esteban JA, Avila J (2011) Microtubule-associated protein 1B (MAP1B) is required for dendritic spine development and synaptic maturation. J Biol Chem 286:40638-40648. CrossRef Medline

Traynelis SF, Wollmuth LP, McBain CJ, Menniti FS, Vance KM, Ogden KK, Hansen KB, Yuan H, Myers SJ, Dingledine R (2010) Glutamate receptor ion channels: structure, regulation, and function. Pharmacol Rev 62:405496. CrossRef Medline

Tymanskyj SR, Scales TM, Gordon-Weeks PR (2012) MAP1B enhances microtubule assembly rates and axon extension rates in developing neurons. Mol Cell Neurosci 49:110-119. CrossRef Medline

Verhaegen M, Bauer JA, Martin de la Vega C, Wang G, Wolter KG, Brenner JC, Nikolovska-Coleska Z, Bengtson A, Nair R, Elder JT, Van Brocklin M, Carey TE, Bradford CR, Wang S, Soengas MS (2006) A novel BH3 mimetic reveals a mitogen-activated protein kinase-dependent mechanism of melanoma cell death controlled by p53 and reactive oxygen species. Cancer Res 66:11348-11359. CrossRef Medline

Wang Z, Edwards JG, Riley N, Provance DW Jr, Karcher R, Li XD, Davison IG, Ikebe M, Mercer JA, Kauer JA, Ehlers MD (2008) Myosin Vb mobilizes recycling endosomes and AMPA receptors for postsynaptic plasticity. Cell 135:535-548. CrossRef Medline

Webster DR, Gundersen GG, Bulinski JC, Borisy GG (1987) Differential turnover of tyrosinated and detyrosinated microtubules. Proc Natl Acad Sci U S A 84:9040-9044. CrossRef Medline

Wellmann H, Kaltschmidt B, Kaltschmidt C (1999) Optimized protocol for biolistic transfection of brain slices and dissociated cultured neurons with a hand-held gene gun. J Neurosci Methods 92:55-64. CrossRef Medline

Wyszynski M, Valtschanoff JG, Naisbitt S, Dunah AW, Kim E, Standaert DG, Weinberg R, Sheng M (1999) Association of AMPA receptors with a subset of glutamate receptor-interacting protein in vivo. J Neurosci 19: 6528-6537. Medline

Wyszynski M, Kim E, Dunah AW, Passafaro M, Valtschanoff JG, Serra-Pagès C, Streuli M, Weinberg RJ, Sheng M (2002) Interaction between GRIP and liprin-alpha/SYD2 is required for AMPA receptor targeting. Neuron 34:39-52. CrossRef Medline

Zauner W, Kratz J, Staunton J, Feick P, Wiche G (1992) Identification of two distinct microtubule binding domains on recombinant rat MAP 1B. Eur J Cell Biol 57:66-74. Medline

Zheng N, Jeyifous O, Munro C, Montgomery JM, Green WN (2015) Synaptic activity regulates AMPA receptor trafficking through different recycling pathways. eLife 4 . 